Article

\title{
Antimicrobial Potential and Phytochemical Profile of Wild and Cultivated Populations of Thyme (Thymus sp.) Growing in Western Romania
}

\author{
Rodica Beicu ${ }^{1}$, Ersilia Alexa ${ }^{2, * D}$, Diana Obiștioiu ${ }^{3, *(D)}$, Ileana Cocan ${ }^{2}$, Florin Imbrea ${ }^{4}$, Georgeta Pop ${ }^{4}$, \\ Denisa Circioban ${ }^{5}\left(\mathbb{D}\right.$, Cristian Moisa ${ }^{6}\left(\mathbb{D}\right.$, Andreea Lupitu ${ }^{6}\left(\mathbb{D}\right.$, Lucian Copolovici ${ }^{6,7}\left(\mathbb{D}\right.$, Dana Maria Copolovici ${ }^{6,7}(\mathbb{D})$ \\ and Ilinca Merima Imbrea 1
}

Citation: Beicu, R.; Alexa, E.; Obiștioiu, D.; Cocan, I.; Imbrea, F.; Pop, G.; Circioban, D.; Moisa, C.; Lupitu, A.; Copolovici, L.; et al. Antimicrobial Potential and Phytochemical Profile of Wild and Cultivated Populations of Thyme (Thymus sp.) Growing in Western Romania. Plants 2021, 10, 1833. https://doi.org/10.3390/plants 10091833

Academic Editor: Stefania Garzoli

Received: 30 July 2021

Accepted: 1 September 2021

Published: 3 September 2021

Publisher's Note: MDPI stays neutral with regard to jurisdictional claims in published maps and institutional affiliations.
1 Faculty of Horticulture and Silviculture, Banat's University of Agricultural Sciences and Veterinary Medicine “King Michael I of România” from Timișoara, Calea Aradului, 119, 300645 Timisoara, Romania; rodica.beicu@usab-tm.ro (R.B.); ilinca_imbrea@usab-tm.ro (I.M.I.)

2 Faculty of Food Engineering, Banat's University of Agricultural Sciences and Veterinary Medicine “King Michael I of România" from Timișoara, Calea Aradului, 119, 300645 Timisoara, Romania; ileanacocan@usab-tm.ro

3 Faculty of Veterinary Medicine, Banat's University of Agricultural Sciences and Veterinary Medicine "King Michael I of România" from Timișoara, Calea Aradului, 119, 300645 Timisoara, Romania

4 Faculty of Agriculture, Banat's University of Agricultural Sciences and Veterinary Medicine "King Michael I of România" from Timișoara, Calea Aradului, 119, 300645 Timisoara, Romania;

florin_imbrea@usab-tm.ro (F.I.); georgeta_pop@usab-tm.ro (G.P.)

5 Department Pharmacy, Faculty of Pharmacy, "Victor Babeş" University of Medicine and Pharmacy, Eftimie Murgu Square, 2, 300041 Timisoara, Romania; circioban.denisa@umft.ro

6 Institute for Research, Development and Innovation in Technical and Natural Sciences, Aurel Vlaicu University, Elena Dragoi St., 310330 Arad, Romania; moisa.cristian@yahoo.com (C.M.); pag.andreea@yahoo.com (A.L.); lucian.copolovici@uav.ro (L.C.); dana.copolovici@uav.ro (D.M.C.)

7 Faculty of Food Engineering, Tourism and Environmental Protection, Aurel Vlaicu University, Elena Dragoi St., 310330 Arad, Romania

* Correspondence: ersiliaalexa@usab-tm.ro (E.A.); dianaobistioiu@usab-tm.ro (D.O.)

\begin{abstract}
The purpose of this study was to analyze the chemical composition and antimicrobial activity of some thymus populations collected from five different locations in Western Romania. The chemical compositions of the essential oils (EOs) were studied through GC-MS, and the biological activities were evaluated using the microdilution method. The EO yield ranged between $0.44 \%$ and $0.81 \%$. Overall, 60 chemical compounds were identified belonging to three chemotypes: thymol (three populations), geraniol (one population) and carvacrol (one population). Thymus vulgaris L. is distinguished by a high content of thymol, while species of spontaneous flora (Th. odoratissimus and Th. pulegioides) contain, in addition to thymol, appreciable amounts of carvacrol and geraniol. The antimicrobial activity of each the five oils was tested on Staphylococcus aureus (ATCC 25923), Streptococcus pyogenes (ATCC 19615), Esherichia coli (ATCC 25922), Pseudomonas aeruginosa (ATCC 27853), Shigella flexneri (ATCC 12022), Salmonella typhimurium (ATCC 14028), Haemophilus influenzae type B (ATCC 10211), Candida albicans (ATCC 10231) and Candida parapsilopsis (ATCC 22019). The EOs showed biological activity on Gram-positive/Gram-negative/fungal pathogens, the most sensitive strains proving to be S. pyogenes, S. flexneri, S. typhimurium and C. parapsilopsis with an MIC starting at $2 \mu \mathrm{LEO} / 100 \mu \mathrm{L}$. The species sensitive to the action of Thymus sp. from culture or spontaneous flora are generally the same, but it should be noted that $T$. odoratissimus has a positive inhibition rate higher than other investigated EOs, regardless of the administered oil concentration. To date, there is no research work presenting the chemical and antimicrobial profiling of T. odoratissimus and the correlations between the antimicrobial potential and chemical composition of wild and cultivated populations of thyme (Thymus sp.) growing in Western Romania.
\end{abstract}

Keywords: Thymus pulegioides L.; Thymus odoratissimus Mill.; Thymus vulgaris L.; essential oil; antimicrobial activity; chemotaxonomy 


\section{Introduction}

The spontaneous species of the Thymus genus emphasize great taxonomical diversity, indicating a natural evolution that allowed the adaptation to various habitats and created the premises of a divergent evolution based on a great genetic variety [1,2].

In cultures, we encounter the species T. vulgaris L., commonly known as culture thyme. The medicinal importance and culinary purposes of this plant have brought it to the attention of botanists over time. The species has been cultivated ever since ancient times, and it is highly recognized as a very important medicinal herb and as a spice. The aerial part of the plant (herba) presents phytotherapeutically importance, as it has stomachic, choleretic, anthelmintic, antiseptic, scarring, diuretic, antidiarrheal and antiviral effects [3-5].

T. pulegioides L., with the same medicinal properties, is frequently found in meadows in the mountainous area, especially non-calcareous, skeletal, poor soils, oak to subalpine floor [6,7]. It has several subspecies present both in Romania [7] and in Europe [8], and it is sometimes difficult to distinguish between them, even by specialists.

T. odoratissimus Mill. is a species with a lower range, compared to the previous species, being found in Europe mainly in the eastern part of the continent [8]. In Romania, the species vegetates in sunny meadows, from the plain to the mountains $[6,7]$.

Thymus-based products are widely used both in human [9] and veterinary [10] medicine as cosmetic and alimentary additives [5]. The essential oil (EO) extracted from wild thyme populations is used in the food industry as a spice, in the pharmaceutical industry as an antimicrobial agent and in the medical field [11-13]. The chemical composition of the $\mathrm{EO}$ varies significantly from one species to another and sometimes even in the same species $[14,15]$.

Previous results have demonstrated that species from Thymus genus are highly polymorphic [16], and more than twenty EO chemotypes were noticed in different species of the genus [17].

The reporting of its chemical composition, but also studies of flora and vegetation, require the precise determination of the species on a given field. The accuracy of the results and the correctness of the interpretation are tightly bound to taxonomical determination. Biochemical tests might offer valid answers and new instruments in taxonomical determinations, especially regarding the Thymus genus.

The phenolic monoterpenes represent the main constituents of EO in the species of the Thymus genus [18]. Among said phenolic compounds, the predominant ones are thymol and carvacrol [18-20]. The EOs have antioxidant [21,22], antimicrobial [23] and antifungal properties [24,25].

Scientific articles suggest that the yield and chemical composition of EOs obtained from Thymus species and subspecies are influenced by multiple factors such as geographic zone, climate and vegetation period $[4,26]$. However, based on the phenolic compounds found in the EO, the thyme populations can be classified, according to specialty studies, into several chemotypes $[4,14,18]$.

Th literature mentions several scientific studies regarding the chemical characteristics of the spontaneous populations of wild thyme around the globe: France [14], Morocco [27], Iran [28], Serbia and Romania [29], Uzbekistan [30], etc. Among this species, T. odoratissimus (syn. T. glabrescens) and T. pulegioides were proven to be widely dispersed, adapting to different circumstances, and EO diversity was considerable [31].

In recent times, research in Romania has focused on cultivated species of the genus Thymus, especially T. vulgaris [32-34], including species of spontaneous flora, but cultivated on small areas [35], and less on species that grow spontaneously, harvested in situ from the western part of the country. Additionally, the study of antimicrobial effects on Grampositive and Gram-negative bacteria and fungi of Thymus species from spontaneous flora is of interest in the context of promoting natural medicine as an alternative to synthetic antibiotics. The microorganisms used in this paper are capable of causing diseases in the human body that can sometimes be fatal. Two Gram-positive strains (S. pyogenes and S. aureus), 
five Gram-negative strains (H. influenza, S. typhimurium, E. coli, P. aeruginosa, S. flexneri) and two fungal species (Candida parapsilosis and C. albicans) were chosen. Microbes such as bacteria, molds and yeasts are employed in food production and as food ingredients, such as the production of wine, beer and bakery and dairy products. On the other hand, the growth and contamination of spoilage and pathogenic microorganisms is considered to be one of the main causes of foodstuff loss nowadays. Lorenzo et al. [36] present in their study, published in 2018, the most important bacterial and fungal strains involved in food spoilage or contamination, foodborne diseases, resistance to thermal processing and occurrence in different outbreaks, the strains selected in our research covering all these main groups.

The study is carried out with the following research directions: (i) obtaining EOs and determining their chemical composition using GC-MS; (ii) testing the biological activity of the EOs on the selected microorganisms; (iii) analyzing the existence of a correlation between the studied parameters.

\section{Results and Discussion}

\subsection{EO Yield and Composition}

Hydrodistillation of aerial parts of five populations of Thymus sp., harvested from five distinct areas of Banat, Romania, namely T. odoratissimus Mill. (one population), T. pulegioides L. (three populations) and T. vulgaris L. culture (one population), gave yellow and brown colored EOs, characterized by a typical odor, with a yield of $0.62 \%, 0.46 \%$, $0.44 \%, 0.49 \%$ and $0.81 \%$ (reported by weight of dry vegetable mass) for the samples from $\mathrm{TgS}, \mathrm{TpP}, \mathrm{TpC}, \mathrm{TpB}$ and TvL, respectively (Table 1). The overlayed chromatograms of the obtained EOs are shown in Figure 1, and the chemical composition is presented in Table 2. The individual chromatograms of each EOs are presented in Supplementary Materials S1.

Table 1. The yield and color of the EOs isolated from the aerial part of Thymus populations collected from five areas in Banat.

\begin{tabular}{|c|c|c|c|c|}
\hline Population & EO Abbreviation & Location & EO Yield (\%) & EO Color \\
\hline T. odoratissimus Mill. & $\operatorname{TgS}$ & Silagiu & $0.620 \pm 0.012$ & Brown \\
\hline T. pulegioides L. & $\mathrm{TpP}$ & Prigor & $0.460 \pm 0.033$ & Brown-yellow \\
\hline T. pulegioides L. & $\mathrm{TpC}$ & Carasova & $0.440 \pm 0.021$ & Yellow \\
\hline T. pulegioides L. & TpB & Bazias & $0.490 \pm 0.017$ & Pale-yellow \\
\hline T. vulgaris L. & TvL & Lovrin & $0.810 \pm 0.042$ & Brown-yellow \\
\hline
\end{tabular}




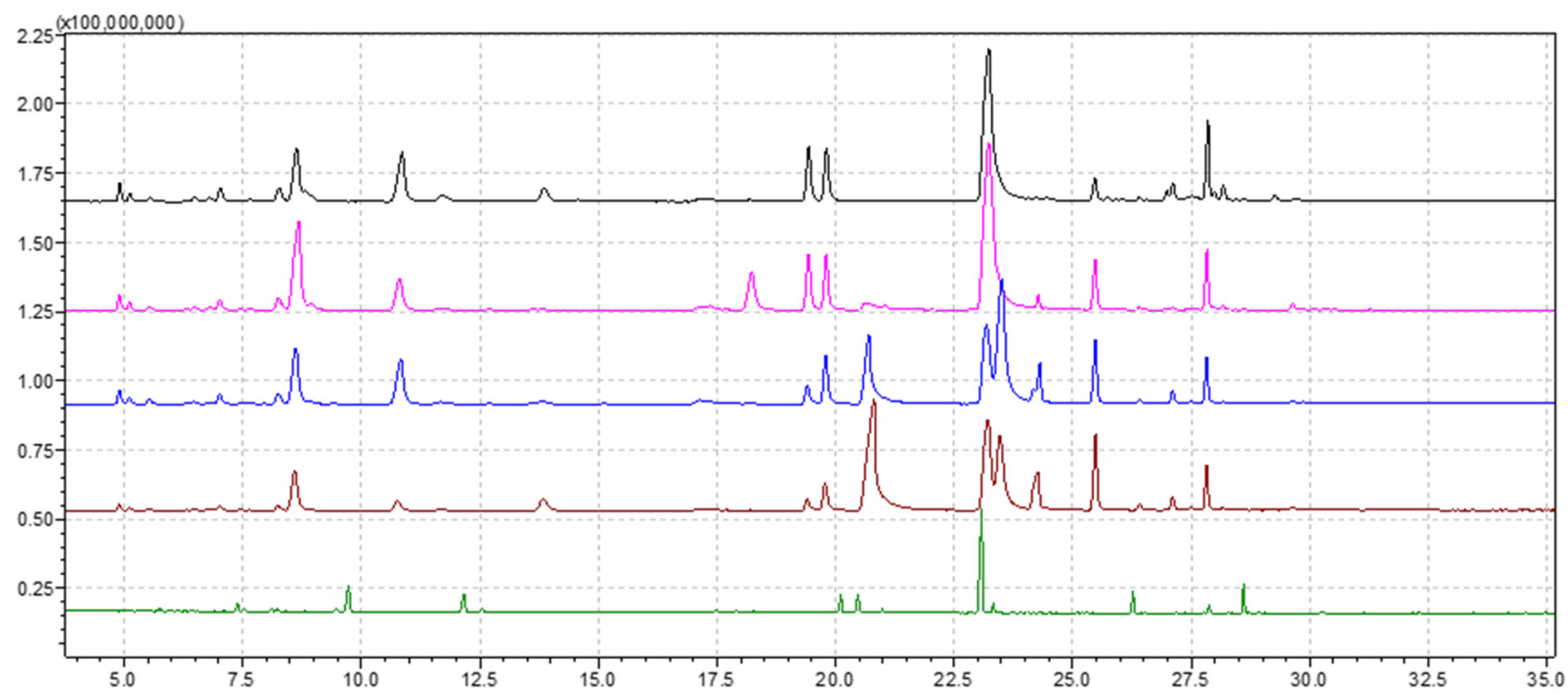

Figure 1. Chromatograms obtained for the EOs extracted from each thyme population: T. odoratissimus (TgS)—black; T. pulegioides (TpP)—pink; T. pulegioides (TpC)—blue; T. pulegioides (TpB)—red; T. vulgaris (TvL)—green.

Table 2. Chemical composition of the EOs isolated from aerial part of the Thymus population collected from five areas in Banat: $T$. odoratissimus (TgS); T. pulegioides (TpP); T. pulegioides (TpC); T. pulegioides (TpB); T. vulgaris (TvL).

\begin{tabular}{|c|c|c|c|c|c|c|c|c|c|}
\hline Nr Crt & $\mathbf{R i}^{a}$ & $\mathbf{R i}^{\mathbf{b}}$ & Compound & Classes & TgS & $\mathrm{TpP}$ & $\mathrm{TpC}$ & TpB & TvL \\
\hline 1 & 930 & 930 & $\alpha$-Thujene & $\mathrm{MH}$ & 1.42 & 1.12 & 1 & 0.5 & 0.63 \\
\hline 2 & 939 & 939 & $\alpha$-Pinene * & $\mathrm{MH}$ & 0.67 & 0.59 & 0.5 & 0.25 & 0.5 \\
\hline 3 & 954 & 954 & Camphene & $\mathrm{MH}$ & 0.38 & 0.36 & 0.42 & 0.21 & \\
\hline 4 & 975 & 975 & Sabinene * & MH & 0.06 & 0.1 & 0.09 & 0.04 & \\
\hline 5 & 979 & 983 & $\beta$-Pinene * & $\mathrm{MH}$ & 1.63 & 1.03 & 1.01 & 0.48 & 0.52 \\
\hline 6 & 990 & 987 & $\beta$-Myrcene $*$ & $\mathrm{MH}$ & & & 0.08 & & \\
\hline 7 & 1002 & 993 & $\alpha$-Phellandrene * & MH & 0.31 & 0.21 & 0.16 & & \\
\hline 8 & 1011 & 1002 & 3-Carene * & $\mathrm{MH}$ & 0.07 & 0.06 & 0.04 & & \\
\hline 9 & 1012 & 1010 & 4-Carene & $\mathrm{MH}$ & 1.86 & 1.6 & 1.3 & 0.57 & \\
\hline 10 & 1020 & 1019 & D-Limonene * & $\mathrm{MH}$ & & & & 0.23 & \\
\hline 11 & 1023 & 1020 & $m$-Cymene & MH & & & 8.45 & 6.3 & \\
\hline 12 & 1024 & 1021 & p-Cymene & $\mathrm{MH}$ & 8.55 & 15.12 & 0.43 & & 10.94 \\
\hline 13 & 1037 & 1027 & cis- $\beta$-Ocimene * & MH & 0.22 & 0.99 & & & \\
\hline 14 & 1050 & 1038 & trans- $\beta$-Ocimene * & $\mathrm{MH}$ & & & 0.06 & & \\
\hline 15 & 1059 & 1069 & $\gamma$-Terpinene & $\mathrm{MH}$ & 8.96 & 5.14 & 7.47 & 1.68 & 8.5 \\
\hline 16 & 1070 & 1085 & cis-Sabinene hydrate & MH & 1.69 & 0.55 & 0.49 & 0.2 & 1.27 \\
\hline 17 & 1088 & 1107 & $\alpha$-Terpinolene & MH & 0.1 & 0.16 & & & 1.04 \\
\hline 18 & 1299 & 1295 & Carvacrol ${ }^{*}$ & $\mathrm{MO}$ & 7.94 & 5.71 & 25.43 & 15.92 & 2.58 \\
\hline 19 & 1235 & 1238 & Thymyl methyl ether & $\mathrm{MO}$ & 6.34 & 5.88 & 2.05 & 1.6 & 5.27 \\
\hline 20 & 1244 & 1250 & Carvacrol methyl ether & $\mathrm{MO}$ & 6.67 & 5.73 & 5.54 & 3.81 & 5.24 \\
\hline 21 & 1290 & 1290 & Thymol & $\mathrm{MO}$ & 30.82 & 33.81 & 13.93 & 17.14 & 40.85 \\
\hline 22 & 1096 & 1121 & Linalool & $\mathrm{MO}$ & 2.84 & & 0.77 & 2.27 & \\
\hline 23 & 1146 & 1140 & Camphor & $\mathrm{MO}$ & & & 0.08 & & \\
\hline 24 & 1169 & 1168 & endo-Borneol & $\mathrm{MO}$ & 0.62 & 0.55 & 0.86 & 0.47 & 0.7 \\
\hline 25 & 1160 & 1170 & Isoborneol & $\mathrm{MO}$ & & & 0.55 & & \\
\hline 26 & 1177 & 1171 & Terpinen-4-ol & $\mathrm{MO}$ & 0.68 & 0.79 & & 0.38 & \\
\hline 27 & 1188 & 1190 & $\alpha$-Terpineol & $\mathrm{MO}$ & & 6.29 & & & \\
\hline 28 & 1252 & 1259 & cis-Geraniol & $\mathrm{MO}$ & & 1.88 & 13.12 & 28.35 & \\
\hline 29 & 1257 & 1263 & Linalyl acetate & $\mathrm{MO}$ & & & & & 0.72 \\
\hline 30 & 1285 & 1287 & Borneol acetate & $\mathrm{MO}$ & & 0.56 & & & \\
\hline
\end{tabular}


Table 2. Cont.

\begin{tabular}{|c|c|c|c|c|c|c|c|c|c|}
\hline Nr Crt & $\mathbf{R i}^{\mathbf{a}}$ & $\mathbf{R i}^{\mathbf{b}}$ & Compound & Classes & TgS & TpP & TpC & TpB & TvL \\
\hline 31 & 1381 & 1390 & cis-Geranyl acetate & $\mathrm{MO}$ & & 0.72 & 3.33 & 5.7 & \\
\hline 32 & 1271 & 1280 & Lavandulol acetate & $\mathrm{MO}$ & & & 1.22 & & \\
\hline 33 & 1422 & 1423 & Lavandulyl isobutyrate & $\mathrm{MO}$ & & & & 0.13 & \\
\hline 34 & 1591 & 1603 & $\begin{array}{c}\text { (R)-Lavandulyl } \\
\text { (R)-2-methylbutanoate }\end{array}$ & $\mathrm{MO}$ & & & & 0.12 & \\
\hline 35 & & & Dihydro-1,8-cineole & $\mathrm{MO}$ & 0.49 & 0.41 & 0.25 & & \\
\hline 36 & 980 & 984 & 3-Octanol & others & & 0.12 & & & 0.66 \\
\hline 37 & 963 & 963 & 3-Octanone & others & & & & & 2.6 \\
\hline 38 & & & $\begin{array}{l}\text { 1-Methyl-4-(methylethyl)-(E)-2- } \\
\text { cyclohexenol }\end{array}$ & others & 1.95 & & & & \\
\hline 39 & & & $\begin{array}{c}\text { 4,8,8-Trimethyl-2-methylene-4- } \\
\text { vinylbicyclo[5.2.0] } \\
\text { nonane }\end{array}$ & others & 2.39 & & & & \\
\hline 40 & & & $\begin{array}{l}\text { Unidentified } \\
\text { Methyl-3- }\end{array}$ & others & & & & & 0.3 \\
\hline 41 & & & $\begin{array}{c}\text { methylenetricyclo[4.4.0.02,7] } \\
\text { decane }\end{array}$ & others & 0.43 & & & & \\
\hline 42 & & & Unidentified & others & & 0.22 & & & \\
\hline 43 & & & Unidentified & others & & & 0.33 & 0.37 & \\
\hline 44 & 977 & 977 & 1-Octen-3-ol & others & 0.52 & 0.4 & 0.23 & 0.23 & 0.84 \\
\hline 45 & 1110 & 1123 & $\begin{array}{l}\text { 3-Octanol acetate } \\
\text { cis-4,11,11-Trimethyl-8- }\end{array}$ & others & 0.21 & & & & \\
\hline 46 & & & $\begin{array}{l}\text { methylenebicyclo(7.2.0)undeca } \\
\text {-4-ene (cis-caryophyllene) }\end{array}$ & $\mathrm{SH}$ & 6.51 & & 3.45 & 3.68 & \\
\hline 47 & & & Isoledene & $\mathrm{SH}$ & 1.46 & & 0.23 & 0.29 & \\
\hline 48 & & & $\alpha$-Muurolene & $\mathrm{SH}$ & 0.6 & & 0.1 & & \\
\hline 49 & & & $\beta$-Bisabolene & $\mathrm{SH}$ & & & & & 7.54 \\
\hline 50 & & & $\gamma$-Cadinene & $\mathrm{SH}$ & & & & & 0.17 \\
\hline 51 & 1408 & 1410 & Isocaryophyllene & $\mathrm{SH}$ & & & 5.22 & 6.83 & \\
\hline 52 & 1419 & 1420 & Caryophyllene * & $\mathrm{SH}$ & & 4.19 & & & 5.98 \\
\hline 53 & 1376 & 1380 & $\alpha$-Copaene & $\mathrm{SH}$ & 0.9 & 0.4 & & & \\
\hline 54 & 1454 & 1456 & Humulene & $\mathrm{SH}$ & & 0.24 & 0.37 & 0.53 & \\
\hline 55 & 1479 & 1483 & gamma-Muurolene & $\mathrm{SH}$ & 0.83 & 0.14 & 0.05 & & \\
\hline 56 & 1481 & 1485 & Germacrene D & $\mathrm{SH}$ & 1.88 & 0.18 & 1.05 & 1.25 & 2.24 \\
\hline 57 & 1441 & 1442 & Aromadendrene & $\mathrm{SH}$ & & 4.14 & & & \\
\hline 58 & 1432 & 1435 & $\beta$-copaene & $\mathrm{SH}$ & & & & & 0.61 \\
\hline 59 & 1583 & 1584 & Caryophyllene oxide & $\mathrm{SO}$ & & & 0.34 & & \\
\hline 60 & 1640 & 1638 & Cadinol & $\mathrm{SO}$ & & & & 0.07 & \\
\hline TOTAL & & & & & 100 & 99.39 & 100 & 99.6 & 99.7 \\
\hline \multicolumn{5}{|c|}{ Total of Major Compounds } & $\begin{array}{l}\text { TgS } \\
\text { Area } \\
(\%)\end{array}$ & TpP & $\mathrm{TpC}$ & TpB & TvL \\
\hline \multicolumn{5}{|c|}{ Monoterpene hydrocarbonates (MH) } & 25.92 & 27.03 & 21.5 & 10.46 & 23.4 \\
\hline \multicolumn{5}{|c|}{ Monoterpene oxygenate (MO) } & 56.4 & 62.33 & 67.13 & 75.89 & 55.36 \\
\hline \multicolumn{5}{|c|}{ Total Monoterpene } & 82.32 & 89.36 & 88.63 & 86.35 & 78.76 \\
\hline \multicolumn{5}{|c|}{ Sesquiterpene hydrocarbonates $(\mathrm{SH})$} & 12.18 & 9.29 & 10.47 & 12.58 & 16.54 \\
\hline \multicolumn{5}{|c|}{ Sesquiterpene oxygenate $(\mathrm{SO})$} & 0 & 0 & 0.34 & 0.07 & 0 \\
\hline \multicolumn{5}{|c|}{ Total Sesquiterpene } & 12.18 & 9.29 & 10.81 & 12.65 & 16.54 \\
\hline \multicolumn{5}{|c|}{ Others } & 5.5 & 0.74 & 0.56 & 0.6 & 4.4 \\
\hline \multicolumn{5}{|c|}{ TOTAL } & 100 & 99.39 & 100 & 99.6 & 99.7 \\
\hline
\end{tabular}

$\mathrm{RI}^{\mathrm{a}}$ : retention indices were calculated in this study and were determined relative to the retention times $\left(\mathrm{t}_{\mathrm{R}}\right)$ values of $n$-alkanes (C10-C35); $\mathrm{RI}^{\mathrm{b}}$ : retention indices from the literature. The names of the compounds identified also by comparison with standards are indicated with an asterisk $(*)$.

In total, 60 compounds were detected ( 32 for $\mathrm{TgS}, 33$ for $\mathrm{TpP}, 36$ for $\mathrm{TpC}, 29$ for $\mathrm{TpB}$ and 23 for TvL), phenolic compounds being the main substances in all analyzed EOs. The chemical compounds found in the EOs extracted from five thyme populations can be 
divided into three different chemotypes. Three EOs were characterized by high amounts of thymol (TgS-30.82\%, TpP-33.81\% and TvL-40.85\%) and can be classified as EOs belonging to the thymol chemotype. One EO revealed carvacrol to be the main chemical compound (TpC-25.43\%) and it can be classified as an EO belonging to the carvacrol chemotype, and one EO was assessed to have cis-geraniol as the main chemical compound (TpB), which can be classified as belonging to the geraniol chemotype. Linalool, which is considered to be responsible for antimicrobial [37,38] and antifungal activity [37] of EOs by interfering with biofilm formation and stability [39], was identified in three populations of thyme. Our results were in agreement with previous studies, which showed that T. pulegioides has a chemical polymorphism with different chemotypes $[17,40]$ that show spatial segregation in nature: phenolic chemotypes (carvacrol, thymol) and non-phenolic chemotypes (geraniol, alpha-terpineol or linalool) [41,42].

Additionally, for T. odoratissimus, the monoterpene fraction (82.32\%) was constituted by monoterpene hydrocarbons $(25.92 \%)$, among which the main representatives were $p$-cymene $(8.55 \%)$ and $\gamma$-terpinene $(8.96 \%)$. Among oxygen-containing monoterpenes $(56.4 \%)$, linalool $(2.84 \%)$ was the most abundant. Germacrene D $(1.88 \%)$ was the main component of the sesquiterpene fraction. Furthermore, several phenolic monoterpene compounds (51.77\%) with high biological importance were found to have significant prevalence values, namely thymol $(30.82 \%)$, carvacrol $(7.94 \%)$, carvacrol methyl ether $(6.67 \%)$ and thymol methyl ether $(6.34 \%)$.

The EO obtained from T. pulegioides in Prigor (TpP) was mainly constituted by thymol (33.81\%). The monoterpene fraction $(89.36 \%)$ comprised hydrocarbons $(27.03 \%)$ with p-cymene $(15.12 \%)$ as the predominant component. Among oxygen-containing monoterpenes $(62.33 \%)$, although thymol was the most abundant compound $(33.81 \%)$, the presence of $\alpha$-terpineol (6.29\%) is also important to stipulate. Caryophyllene $(4.19 \%)$ and aromadendrene $(4.14 \%)$ represented the main sesquiterpene hydrocarbons.

In the T. pulegioides EO from Carasova (TpC), among the compounds found within the monoterpene fraction, carvacrol (25.43\%) and thymol (13.93\%) were the most abundant ones. Regarding the monoterpene fraction, a significant difference was determined. As such, the monoterpene hydrocarbons were found to have a relatively high prevalence $(21.50 \%)$, among which the main representatives were $m$-cymene $(8.45 \%)$ and $\gamma$-terpinene $(7.47 \%)$. The oxygen-containing monoterpenes $(67.13 \%)$, among which the main nonphenolic representatives were cis-geraniol $(13.12 \%)$ and cis-geranyl acetate $(3.33 \%)$, were present in a significant percentage. Isocaryophyllene (5.22\%) was the main component of the sesquiterpene fraction of the EO, followed by germacrene $\mathrm{D}(1.05 \%)$.

The EO from T. pulegiodes collected from Bazias (TpB) presented a different composition. In this EO, monoterpenes constituted the most abundant fraction $(86.35 \%)$, with a prevalence of monoterpene hydrocarbons $(10.46 \%)$ and oxygen-containing monoterpenes $(75.89 \%)$, with a great amount of cis-geraniol $(28.35 \%)$, as well as the phenols thymol $(17.14 \%)$ and carvacrol (15.21\%). Among sesquiterpenes, only isocaryophyllene (6.83\%) was present in an appreciable amount.

The three studied EOs from T. pulegioides were quite different regarding the relative percentage of the main components; thymol was predominant in T. pulegioides collected from Prigor, while carvacrol and geraniol were only $5.71 \%$ and $1.88 \%$, respectively. Moreover, carvacrol is the main phenolic compound in T. pulegioides from Carasova, and geraniol was the predominant compound in T. pulegioides from Bazias. These differences in the EO of T. pulegioides confirmed that the species of the genus Thymus are taxonomically and genetically complex [37]. Previous papers on the EOs of T. pulegioides concluded that there is no clear chemical relation between different varieties of this species and chemotypes [43], so it is recommended and useful to expand this study area regarding Thymus genus.

The EO of T. vulgaris, the cultivated species of thyme, collected from Lovrin, was characterized by high percentages of thymol chemotype $(40.85 \%)$. The monoterpene hydrocarbons were quite similar to the other EOs $(23.40 \%)$. $p$-Cymene $(10.94 \%)$ and $\gamma$-terpinene $(8.50 \%)$ were the main compounds, while the oxygenated monoterpenes 
represented $55.36 \%$. Caryophyllene (5.98\%) was the main component of the sesquiterpene fraction of the EO, followed by germacrene D $(2.24 \%)$.

Therefore, six chemotypes were identified in a culture of T. vulgaris in France, based on the diversity of the EOs (geraniol, linalool, $\alpha$-terpineol, thuyanol-4, thymol and carvacrol), with stable specific characters in both natural habitats and experimental cultures, which can also be passed on via inheritance [14]. These "chemical species" are considered intraspecific, the species being homogenous by morphologic and karyotypical criteria, and the distribution frequency of these chemotypes is due to the ecological and genetic factors, especially climatic factors [14]. The presence of some phytochemical chemotypes has been reported in other species of the Thymus genus as well [4,26].

Among this species, T. odoratissimus (syn. T. glabrescens) and T. pulegioides were proven to be widely dispersed, adapting to different circumstances, and the EO diversity was considerable [31].

For example, T. pulegioides has been characterized by a highly polymorphic chemical level $[16,40]$. Previous results have demonstrated that this species is polymorphic [16], and eight chemotypes have been determined $[17,36]$. The thymol/carvacrol chemotype is one of the most frequent in Italy [41].

\subsection{Antimicrobial Activity}

Figure 2 presents the microdilution method results of the EOs tested, expressed as the bacterial growth rate (BGR \%), calculated according to Formula (1), and mycelial growth rate (MGR \%), calculated according to Formula (3), both defined in the Materials and Methods section. Figure 3 shows the bacterial inhibition rate (BIR \%)/mycelial inhibition rate (MIR \%) calculated according to Formulas (2) and (4), defined in the Materials and Method section. All values presented below the baseline in Figure 3 represent a strainboosting effect. Table 3 presents the optical density (OD) of EOs at different concentrations applied on the selected bacterial and fungal strains, as is described in Section 3.4. The MIC $(\mu \mathrm{L} \mathrm{EO} / 100 \mu \mathrm{L})$ values are presented in Table 4.

Reported as BGR/MGR\%, the microbialgrowth rate is the growth of the bacterial $/ \mathrm{micelial}$ mass, where growth was identified by spectophotometric measurement, while BIR/MIR $\%$ represents the bacterial/micelial wheremass loss after the inhibitory effect of EOs, was registered through spectrophotometric measurements. Concerning the effect of the tested EOs on the bacterial/fungal strains, the registered effect is either a strain-boosting effect, where the bacterial/micelial mass growth of the strain affected by the oil is larger than that found in the case of the simple strain, which is therefore a potentiating effect, or an inhibitory effect, in which case the mass growth of the bacterial/micelial strain is lower than that reported for the simple strain.

Concerning the antibacterial activity of $\mathrm{TgS}$, the evolution is in close correlation with the concentration used, $\mathrm{TgS}$ presenting a general inhibitory activity. The most affected strains were S. flexneri, S. typhimurium and S. pyogenes. For S. flexneri the growth rate (BGR), depending on the concentration, varied from $24.90 \%$ to $35.67 \%$ (Figure 2A), with an inhibition rate (BIR\%) ranging from $64.33 \%$ to $75.10 \%$ compared to the negative control (Figure $3 \mathrm{~A}$ ). BGR $\%$ ranged between $29.89 \%$ and $41.45 \%$ (with an inhibitory percentage ranging from $58.55 \%$ to $70.11 \%$ BIR) in the case of S. typhimurium. The inhibitory effect of $\mathrm{TgS}$ was also detected when other bacterial strains were tested, but with a lower inhibition rate. 


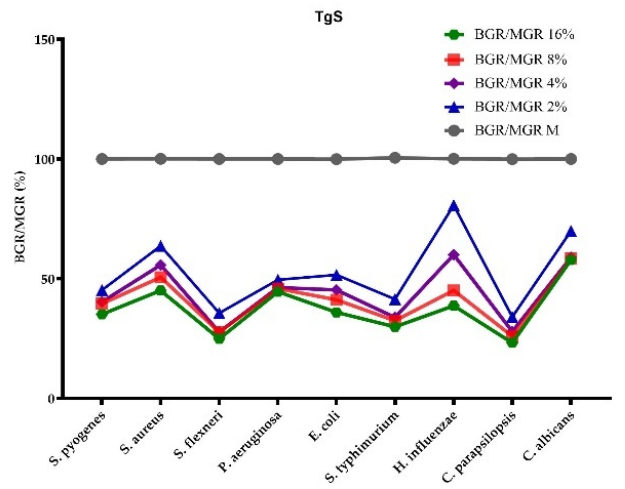

Atccsinains

(A) Antimicrobial activity (expressed as BGR/MGR\%) of TgS

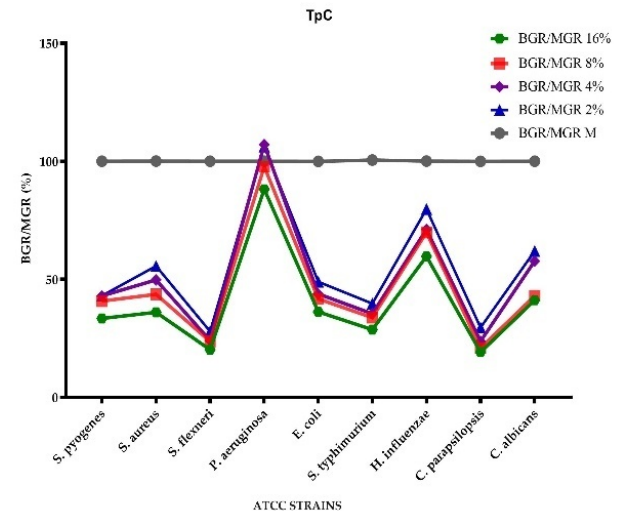

(C) Antimicrobial activity (expressed as BGR/MGR\%) of $\mathrm{TpC}$

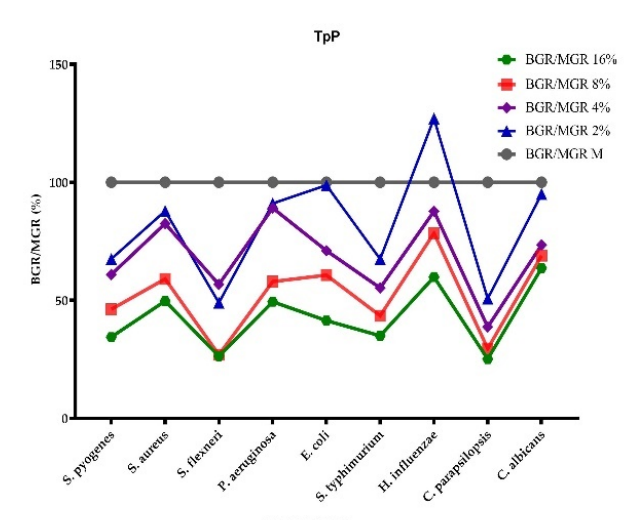

(B) Antimicrobial activity (expressed as BGR/MGR\%) of $\mathrm{TpP}$

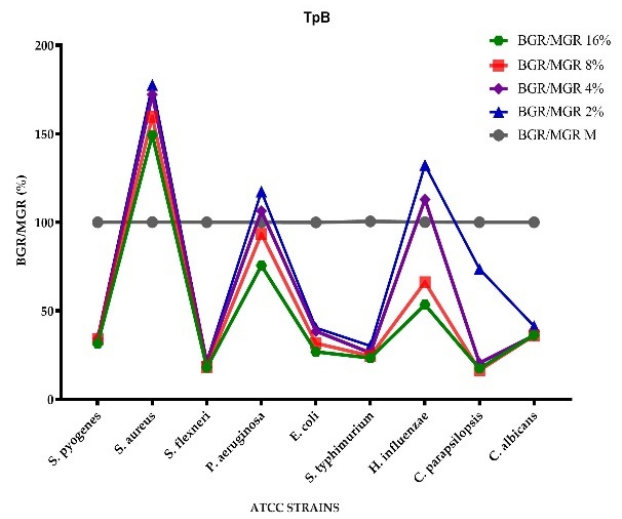

(D) Antimicrobial activity (expressed as BGR/MGR\%) of $\mathrm{TpB}$

TvL

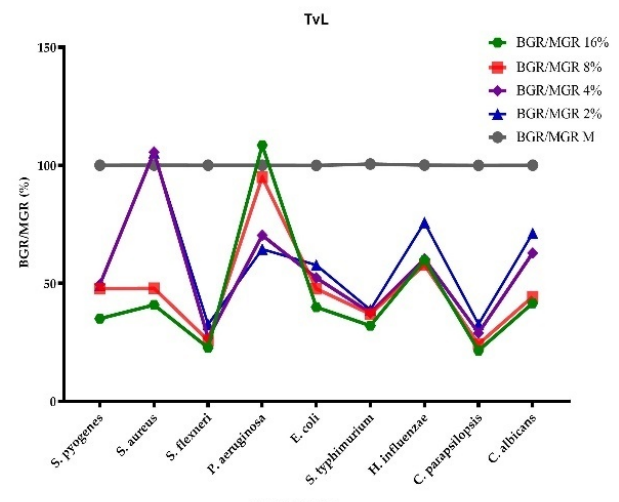

atcC STRAins

(E) Antimicrobial activity (expressed as BGR/MGR\%) of TvL

Figure 2. Antimicrobial activity of analyzed EOs expressed as BGR/MGR (\%): (A) TgS; (B) TpB; (C) TpC; (D) TpP; (E) TvL. 


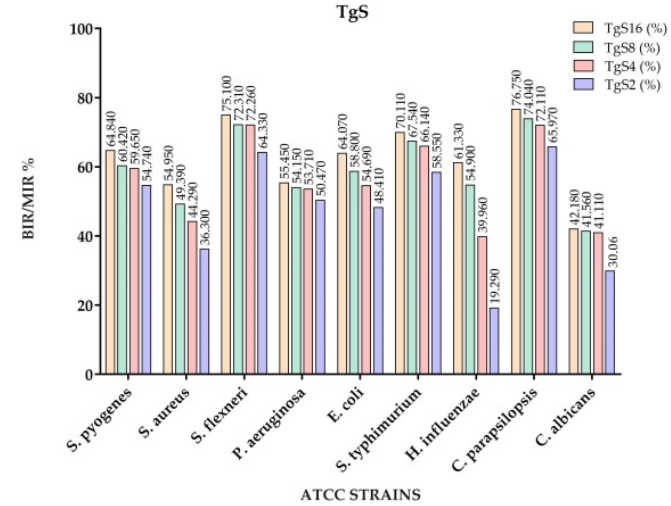

(A) Antimicrobial activity (expressed as $\mathrm{BIR} / \mathrm{MIR} \%$ ) of $\mathrm{TgS}$

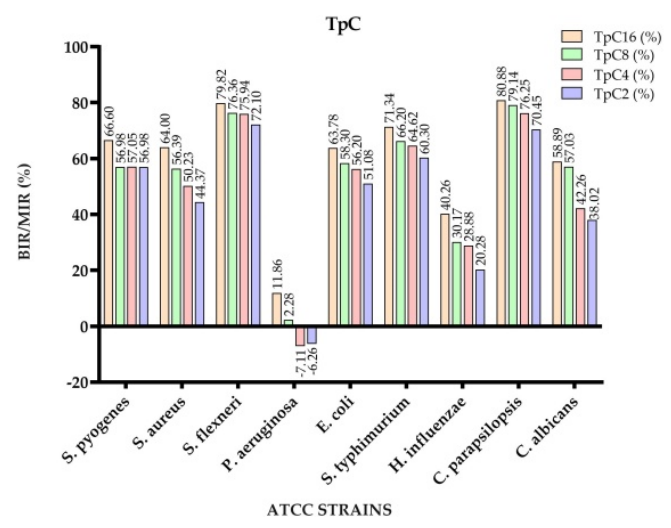

(C) Antimicrobial activity (expressed as $\mathrm{BIR} / \mathrm{MIR} \%$ ) of $\mathrm{TpC}$

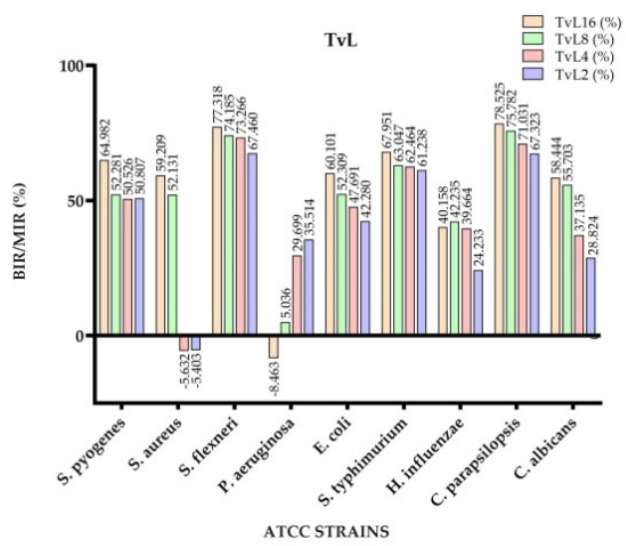

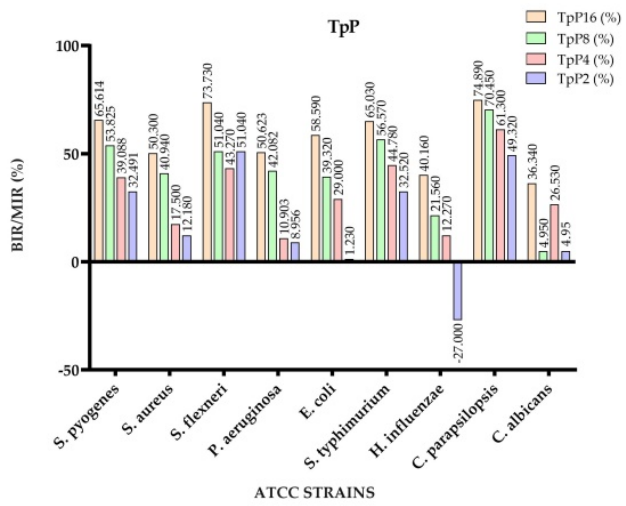

(B) Antimicrobial activity (expressed as $\mathrm{BIR} / \mathrm{MIR} \%$ ) of $\mathrm{TpP}$

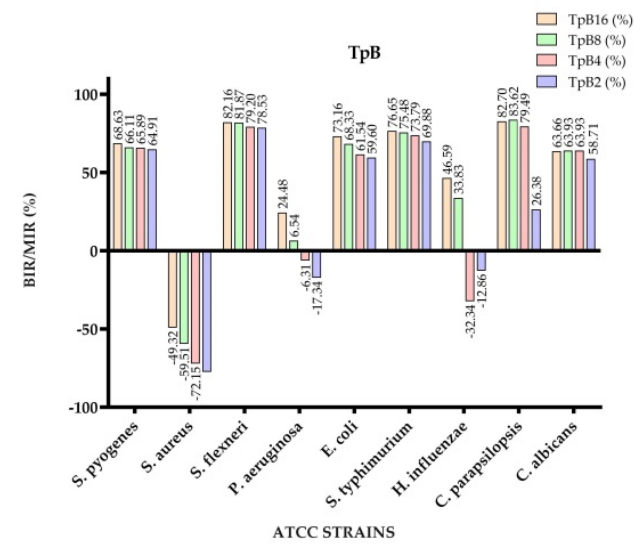

(D)Antimicrobial activity (expressed as $\mathrm{BIR} / \mathrm{MIR} \%$ ) of $\mathrm{TpB}$

(E) Antimicrobial activity (expressed as BIR/MIR\%) of TvL

Figure 3. Antimicrobial activity of analyzed EOs expressed as BIR/MIR (\%): (A) TgS; (B) TpB; (C) TpC; (D) TpP; (E) TvL. 
Table 3. The optical density (OD) mean values of EOs at $540 \mathrm{~nm}$.

\begin{tabular}{|c|c|c|c|c|c|c|c|c|c|}
\hline$\%$ & S.pyogenes & S. aureus & S. flexneri & P. aeruginosa & E. coli & S. typhimurium & H. influenza & C. parapsilopsis & C. albicans \\
\hline TgS16 & $0.167 \pm 0.006^{\mathrm{a}}$ & $0.197 \pm 0.008^{a}$ & $0.199 \pm 0.006^{\mathrm{a}}$ & $0.572 \pm 0.004^{\mathrm{a}}$ & $0.166 \pm 0.001^{\mathrm{a}}$ & $0.171 \pm 0.002^{\mathrm{a}}$ & $0.130 \pm 0.001^{a}$ & $0.201 \pm 0.001^{\mathrm{a}}$ & $0.218 \pm 0.005^{\mathrm{a}}$ \\
\hline $\operatorname{TgS8}$ & $0.188 \pm 0.004^{b}$ & $0.222 \pm 0.001^{b}$ & $0.221 \pm 0.003^{b}$ & $0.589 \pm 0.002^{b}$ & $0.190 \pm 0.007^{b}$ & $0.185 \pm 0.002^{b}$ & $0.152 \pm 0.002^{b}$ & $0.224 \pm 0.005^{b}$ & $0.220 \pm 0.003^{\mathrm{a}}$ \\
\hline TgS4 & $0.192 \pm 0.003^{b}$ & $0.244 \pm 0.004^{c}$ & $0.221 \pm 0.002^{b}$ & $0.594 \pm 0.003^{c}$ & $0.209 \pm 0.004^{c}$ & $0.193 \pm 0.003^{c}$ & $0.202 \pm 0.003^{c}$ & $0.241 \pm 0.002^{\mathrm{c}}$ & $0.222 \pm 0.004^{\mathrm{a}}$ \\
\hline $\mathrm{TgS} 2$ & $0.215 \pm 0.002^{c}$ & $0.279 \pm 0.002^{d}$ & $0.285 \pm 0.001^{c}$ & $0.636 \pm 0.012^{d}$ & $0.238 \pm 0.006^{\mathrm{d}}$ & $0.237 \pm 0.013^{\mathrm{d}}$ & $0.272 \pm 0.003^{\mathrm{d}}$ & $0.294 \pm 0.005^{d}$ & $0.264 \pm 0.005^{b}$ \\
\hline TpP16 & $0.163 \pm 0.005^{\mathrm{a}}$ & $0.218 \pm 0.002^{\mathrm{e}}$ & $0.210 \pm 0.002^{d}$ & $0.634 \pm 0.009^{d}$ & $0.191 \pm 0.001^{b}$ & $0.200 \pm 0.001^{\mathrm{e}}$ & $0.202 \pm 0.001^{c}$ & $0.217 \pm 0.001^{b}$ & $0.240 \pm 0.003^{c}$ \\
\hline TpP8 & $0.219 \pm 0.004^{\mathrm{c}}$ & $0.259 \pm 0.002^{f}$ & $0.215 \pm 0.002^{\mathrm{e}}$ & $0.744 \pm 0.013^{\mathrm{e}}$ & $0.280 \pm 0.001^{\mathrm{e}}$ & $0.248 \pm 0.003^{\mathrm{d}}$ & $0.264 \pm 0.002^{\mathrm{e}}$ & $0.255 \pm 0.005^{\mathrm{e}}$ & $0.260 \pm 0.003^{d}$ \\
\hline $\mathrm{TpP} 4$ & $0.289 \pm 0.003^{\mathrm{d}}$ & $0.361 \pm 0.001 \mathrm{~g}$ & $0.348 \pm 0.012^{f}$ & $1.144 \pm 0.047^{\mathrm{f}}$ & $0.328 \pm 0.001^{\mathrm{e}}$ & $0.315 \pm 0.004^{\mathrm{f}}$ & $0.296 \pm 0.044^{\mathrm{f}, \mathrm{h}}$ & $0.334 \pm 0.002^{f}$ & $0.277 \pm 0.002^{\mathrm{e}}$ \\
\hline TpP2 & $0.321 \pm 0.001 \mathrm{e}^{\mathrm{e}}$ & $0.385 \pm 0.007^{\mathrm{h}}$ & $0.391 \pm 0.009 \mathrm{~g}$ & $1.169 \pm 0.020^{\mathrm{f}, \mathrm{g}}$ & $0.456 \pm 0.008^{\mathrm{e}}$ & $0.385 \pm 0.008^{g}$ & $0.428 \pm 0.004^{g}$ & $0.437 \pm 0.004 \mathrm{~g}$ & $0.358 \pm 0.001^{\mathrm{f}}$ \\
\hline TpC16 & $0.159 \pm 0.003^{a}$ & $0.158 \pm 0.001^{\mathrm{e}}$ & $0.161 \pm 0.001^{\mathrm{h}}$ & $1.132 \pm 0.055^{\mathrm{f}}$ & $0.167 \pm 0.005^{\mathrm{a}}$ & $0.164 \pm 0.001^{\mathrm{h}}$ & $0.201 \pm 0.003^{c}$ & $0.165 \pm 0.003^{h}$ & $0.155 \pm 0.003 \mathrm{~g}$ \\
\hline $\mathrm{TpC} 8$ & $0.194 \pm 0.001^{b}$ & $0.191 \pm 0.004^{\mathrm{a}}$ & $0.189 \pm 0.001^{\mathrm{i}}$ & $1.255 \pm 0.022^{h, g}$ & $0.193 \pm 0.002^{b}$ & $0.193 \pm 0.002^{c}$ & $0.235 \pm 0.003^{i}$ & $0.180 \pm 0.001^{\mathrm{i}}$ & $0.162 \pm 0.002^{h, j}$ \\
\hline $\mathrm{TpC} 4$ & $0.204 \pm 0.002^{f}$ & $0.218 \pm 0.001^{\mathrm{e}}$ & $0.192 \pm 0.002^{\mathrm{i}}$ & $1.375 \pm 0.066^{\mathrm{i}}$ & $0.202 \pm 0.004^{b}$ & $0.202 \pm 0.001^{\mathrm{e}}$ & $0.240 \pm 0.002^{\mathrm{i}}$ & $0.205 \pm 0.003^{j}$ & $0.218 \pm 0.004^{\mathrm{i}}$ \\
\hline $\mathrm{TpC} 2$ & $0.204 \pm 0.002^{f}$ & $0.244 \pm 0.003^{c}$ & $0.223 \pm 0.002^{j}$ & $1.364 \pm 0.032^{\mathrm{i}}$ & $0.226 \pm 0.009 \mathrm{~d}, \mathrm{f}$ & $0.227 \pm 0.011^{\mathrm{d}}$ & $0.269 \pm 0.012^{\mathrm{e}, \mathrm{h}}$ & $0.255 \pm 0.010^{\mathrm{e}}$ & $0.234 \pm 0.002^{k}$ \\
\hline TpB16 & $0.149 \pm 0.002^{h}$ & $0.654 \pm 0.020^{\mathrm{i}}$ & $0.142 \pm 0.001^{\mathrm{k}}$ & $0.970 \pm 0.024^{j}$ & $0.124 \pm 0.003^{g}$ & $0.133 \pm 0.002^{\mathrm{i}}$ & $0.180 \pm 0.002^{j}$ & $0.149 \pm 0.001^{\mathrm{k}}$ & $0.137 \pm 0.002^{1}$ \\
\hline TpB8 & $0.161 \pm 0.002^{\mathrm{a}}$ & $0.699 \pm 0.019^{j}$ & $0.145 \pm 0.005^{\mathrm{k}}$ & $1.200 \pm 0.025 \mathrm{~g}$ & $0.146 \pm 0.001^{\mathrm{h}}$ & $0.140 \pm 0.001^{j}$ & $0.223 \pm 0.002^{k}$ & $0.141 \pm 0.002^{k}$ & $0.136 \pm 0.003^{1}$ \\
\hline TpB4 & $0.162 \pm 0.001^{\mathrm{a}}$ & $0.754 \pm 0.008^{k}$ & $0.166 \pm 0.001^{1}$ & $1.365 \pm 0.090^{\mathrm{i}}$ & $0.178 \pm 0.004^{b}$ & $0.150 \pm 0.002^{k}$ & $0.446 \pm 0.008^{k}$ & $0.177 \pm 0.003^{1}$ & $0.136 \pm 0.005^{1}$ \\
\hline TpB2 & $0.167 \pm 0.003^{a, g}$ & $0.778 \pm 0.002^{1}$ & $0.171 \pm 0.021^{1}$ & $1.507 \pm 0.019^{k}$ & $0.187 \pm 0.003^{b}$ & $0.172 \pm 0.003^{1}$ & $0.380 \pm 0.003^{1}$ & $0.635 \pm 0.027^{\mathrm{m}}$ & $0.156 \pm 0.009 \mathrm{~g}, j$ \\
\hline TvL16 & $0.166 \pm 0.002^{a, g}$ & $0.179 \pm 0.001^{\mathrm{m}}$ & $0.181 \pm 0.002^{\mathrm{m}}$ & $1.393 \pm 0.050^{\mathrm{i}}$ & $0.184 \pm 0.007^{b}$ & $0.183 \pm 0.000^{b}$ & $0.202 \pm 0.002^{c}$ & $0.185 \pm 0.004^{\mathrm{n}}$ & $0.157 \pm 0.004^{g, j}$ \\
\hline TvL4 & $0.235 \pm 0.002^{f}$ & $0.463 \pm 0.014^{\circ}$ & $0.213 \pm 0.005^{\mathrm{e}}$ & $0.903 \pm 0.018^{1}$ & $0.242 \pm 0.002^{\mathrm{d}, \mathrm{i}}$ & $0.214 \pm 0.003^{\mathrm{m}}$ & $0.203 \pm 0.002^{c}$ & $0.250 \pm 0.001^{\mathrm{e}}$ & $0.237 \pm 0.002 \mathrm{~m}$ \\
\hline TvL2 & $0.234 \pm 0.004^{\mathrm{f}}$ & $0.462 \pm 0.003^{\circ}$ & $0.260 \pm 0.009^{n}$ & $0.828 \pm 0.002^{\mathrm{m}}$ & $0.267 \pm 0.022^{i}$ & $0.221 \pm 0.005^{\mathrm{d}}$ & $0.255 \pm 0.001^{\mathrm{j}, \mathrm{h}}$ & $0.282 \pm 0.003 \mathrm{p}$ & $0.268 \pm 0.002^{n}$ \\
\hline $\mathrm{M}$ & $0.475 \pm 0.005^{\mathrm{i}}$ & $0.438 \pm 0.031^{\circ}$ & $0.798 \pm 0.050^{\circ}$ & $1.284 \pm 0.005^{g}$ & $0.462 \pm 0.021^{\mathrm{e}}$ & $0.574 \pm 0.021^{\mathrm{m}}$ & $0.337 \pm 0.002^{\mathrm{n}}$ & $0.863 \pm 0.005 \mathrm{q}$ & $0.377 \pm 0.004^{\circ}$ \\
\hline
\end{tabular}

The values are expressed as mean values \pm standard deviations of all measurements. Different letters in the columns indicates significant differences $(p<0.05)$ between values according to the $t$-test. 
Table 4. MIC ( $\mu \mathrm{LEO} / 100 \mu \mathrm{L})$ for TgS, TpP, TpC, TpB and TvL.

\begin{tabular}{|c|c|c|c|c|c|c|c|c|c|}
\hline & $\begin{array}{c}\text { S. pyogenes } \\
\text { (ATCC } \\
\text { 19615) }\end{array}$ & $\begin{array}{c}\text { S. aureus } \\
\text { (ATCC } \\
\text { 25923) }\end{array}$ & $\begin{array}{c}\text { S. flexneri } \\
\text { (ATCC } \\
\text { 120022) }\end{array}$ & $\begin{array}{c}\text { P. aerugi- } \\
\text { nosa } \\
\text { (ATCC } \\
\text { 27853) }\end{array}$ & $\begin{array}{c}\text { E. coli } \\
\text { (ATCC } \\
25922)\end{array}$ & $\begin{array}{c}\text { S. ty- } \\
\text { phimurium } \\
\text { (ATCC } \\
\text { 140028) }\end{array}$ & $\begin{array}{c}\text { H. influenzae } \\
\text { type B } \\
\text { (ATCC } \\
\text { 100211) }\end{array}$ & $\begin{array}{l}\text { C.parap- } \\
\text { silopsis } \\
\text { (ATCC } \\
\text { 220019) }\end{array}$ & $\begin{array}{c}\text { C. albicans } \\
\text { (ATCC } \\
\text { 100231) }\end{array}$ \\
\hline $\operatorname{TgS}$ & 16 & 16 & 16 & 16 & 16 & 16 & 16 & 16 & 16 \\
\hline $\mathrm{TgS}$ & 8 & 8 & 8 & 8 & 8 & 8 & 8 & 8 & 8 \\
\hline $\mathrm{TgS}$ & 4 & 4 & 4 & 4 & 4 & 4 & 4 & 4 & 4 \\
\hline $\mathrm{TgS}$ & 2 & 2 & 2 & 2 & 2 & 2 & 2 & 2 & 2 \\
\hline TpP & 16 & 16 & 16 & 16 & 16 & 16 & 16 & 16 & 16 \\
\hline $\mathrm{TpP}$ & 8 & 8 & 8 & 8 & 8 & 8 & 8 & 8 & 8 \\
\hline $\mathrm{TpP}$ & 4 & 4 & 4 & 4 & 4 & 4 & 4 & 4 & 4 \\
\hline $\mathrm{TpP}$ & 2 & 2 & 2 & 2 & 2 & 2 & 2 & 2 & 2 \\
\hline $\mathrm{TpC}$ & 16 & 16 & 16 & 16 & 16 & 16 & 16 & 16 & 16 \\
\hline $\mathrm{TpC}$ & 8 & 8 & 8 & 8 & 8 & 8 & 8 & 8 & 8 \\
\hline $\mathrm{TpC}$ & 4 & 4 & 4 & 4 & 4 & 4 & 4 & 4 & 4 \\
\hline $\mathrm{TpC}$ & 2 & 2 & 2 & 2 & 2 & 2 & 2 & 2 & 2 \\
\hline $\mathrm{TpB}$ & 16 & 16 & 16 & 16 & 16 & 16 & 16 & 16 & 16 \\
\hline $\mathrm{TpB}$ & 8 & 8 & 8 & 8 & 8 & 8 & 8 & 8 & 8 \\
\hline $\mathrm{TpB}$ & 4 & 4 & 4 & 4 & 4 & 4 & 4 & 4 & 4 \\
\hline $\mathrm{TpB}$ & 2 & 2 & 2 & 2 & 2 & 2 & 2 & 2 & 2 \\
\hline TvL & 16 & 16 & 16 & 16 & 16 & 16 & 16 & 16 & 16 \\
\hline TvL & 8 & 8 & 8 & 8 & 8 & 8 & 8 & 8 & 8 \\
\hline TvL & 4 & 4 & 4 & 4 & 4 & 4 & 4 & 4 & 4 \\
\hline TvL & 2 & 2 & 2 & 2 & 2 & 2 & 2 & 2 & 2 \\
\hline
\end{tabular}

The samples that had a strain-boosting effect, maintained with an increase in concentration, are marked in dark grey color. The light grey color represents the samples that had a strain-boosting effect that decreased with the concentration. The white color highlights the samples where the MIC was determined, with the MIC value highlighted. The effect was maintained together with an increase in concentration.

Regarding the antifungal activity, the evolution is also connected to the concentration, and C. parapsilopsis proved to be more sensitive to TgS compared to C. albicans. The MGR\% of C. parapsilopsis was $23.25 \%$ and $34.03 \%$ when $\operatorname{TgS~} 16 \%$ and $\mathrm{TgS} 2 \%$, respectively, were applied, while the MGR\% of C. albicans ranged between 57.82 and $69.94 \%$. The inhibitory effect was proved by MIR\%, with values ranging from 30.06\% to $42.18 \%$ in the case of C. albicans and 65.97-76.75\% for C. parapsilopsis. As an overview, for all the tested strains, TgS MIC proved to be the $2 \mu \mathrm{L}$ EO/100 $\mu \mathrm{L}$ tested concentration, MIC being the lowest compound concentration that yields no visible microorganism growth compared to the control (Table 4). The results of our study were in agreement with the study of Karpinski et al. (2020), on T. vulgaris, in which the MIC value against C. albicans was found between 0.16 and $313 \mu \mathrm{L} / \mathrm{mL}[24]$.

Comparing the BGR percentages, the most sensitive ATCC strains, when TpP is concerned, were S. flexneri, S. pyogenes and S. typhimurium (Figure 2B). For S. flexneri the growth rate (BGR), depending on the concentration, varied from $26.27 \%$ to $48.96 \%$ (Figure $2 \mathrm{~B}$ ), with an inhibition rate (BIR\%) ranging from $51.04 \%$ to $73.73 \%$ compared to the negative control (Figure 3B). Against S. pyogenes the BIR was found between $32.49 \%$ and $65.61 \%$ and between $32.52 \%$ and $65.03 \%$ when the tested strain was S. typhimurium. The concentration influence trend was similar for the other sensitive strains, with BIR in the range of $12.18-50.30 \%$ against $S$. aureus and between $1.23 \%$ and $58.59 \%$ against $E$. coli.

Concerning TpP, our results are in agreement with previous studies in which de Martino et al. [41] showed a sensitivity that increased with the concentration. The concentrations tested through disk diffusion against $S$. aureus, E. coli and P. aeruginosa were found to be in the $0.62-10 \mathrm{mg} / \mathrm{mL}$ range. In our case, the MIC values were determined at $4 \mu \mathrm{L} / 100 \mu \mathrm{L}$ for $H$. influenzae and $2 \mu \mathrm{L} / 100 \mu \mathrm{L}$ for the rest of the tested strains. H. influenzae 
proved to be the only ATCC strain in which the inhibitory effect was not present at a $2 \%$ tested concentration, the evolution of $\mathrm{BIR} \%$, in this case, being negative, therefore proving a boosting bacterial effect with a $-27 \%$ value. The growth rate for $H$. influenzae was concentration-dependent, ranging from $59.84 \%$ up to $127 \%$ (Figure $2 \mathrm{~B}$ ).

In terms of antifungal activity, the inhibition rate showed a better effect on C. parapsilopsis than on C. albicans, values being different by $40 \%$. The less effective antifungal effect against $C$. albicans was demonstrated by the MGR\% values, which ranged from $95.05 \%$ for $\mathrm{TpP}$ tested in a concentration of $2 \%$ to $63.66 \%$ in the case of TpP $16 \%$ (Figure $2 \mathrm{~B}$ ).

The results presented in Figures $2 \mathrm{C}$ and $3 \mathrm{C}$ showed that the best antimicrobial effect recorded by $\mathrm{TpC}(\mathrm{TpC} 2 \%, \mathrm{TpC} 4 \%, \mathrm{TpC} 8 \%$ and $\mathrm{TpC} 16 \%$ ) were against $S$. flexneri (with BGR ranging from $27.90 \%$ to $20.18 \%$ and BIR $72.10-79.82 \%$ ), S. typhimurium (with BGR values of $28.66-39.70 \%$ and BIR values of $60.30-71.34 \%$ ) and S. aureus (with BGR ranging from $36 \%$ to $55.63 \%$ and BIR from 44.37 to $64 \%$ ). The inhibitory effect of TpC against S. pyogenes varied to a small extent with the concentration. The obtained values of BGR were $33.40 \%$ for TpC applied at a concentration of $16 \%$ and $43.20 \%$ in the case of $\mathrm{TpC}$ $2 \%$, and BIR ranging from $56.98 \%$ to $66.60 \%$, depending on the concentration. In this context, Afonso et al. (2018), reported a MIC value of $1.13 \mu \mathrm{L} / 100 \mu \mathrm{L}$ for T. pulegioides against $S$. aureus and $5.75 \mu \mathrm{L} / 100 \mu \mathrm{L}$ against $S$. typhimurium [43]. These results are also in agreement with the data presented by Vaičiulyte et al. that demonstrated in their research (2021) a MIC of $31.3 \mu \mathrm{g} / \mathrm{mL}$ against E. coli and S. aureus [44].

$\mathrm{TpC}$ had a proven growth-boosting effect at $2 \%$ and $4 \%$ concentrations tested against P. aeruginosa with MGR $\%$ values of $107.11 \%$ for TpC $4 \%$ and $106.26 \%$ in the case of TpC $2 \%$. The inhibitory effect started at $8 \%$ concentration, data in correlation with the research done by Afonso et al. (2018), which presented in their study a $5.75 \mu \mathrm{L} \mathrm{EO} / 100 \mu \mathrm{L}$ value as MIC against $P$. aeruginosa [43].

To summarize the data regarding the antifungal activity, $\mathrm{TpC}$ was effective and inhibited both fungal strains. MIR\% ranged in the case of the C. parapsilopsis strain from $26.38 \%$ to $82.70 \%$, and from $58.71 \%$ to $63.66 \%$ in the case of C. albicans. Our results were in agreement with previous studies [24], which presented $0.8 \mu \mathrm{L} / 100 \mu \mathrm{L}$ as MIC against Candida sp., values similar to our findings.

Concerning the antibacterial effect of $\mathrm{TpB}$, the highest inhibitory activity was proved to be against $S$. flexneri, when the BGR $\%$ varied from $17.83 \%$ for $16 \%$ concentration, to $21.47 \%$ for $2 \%$ concentration compared to the control, and BIR $\%$ ranged between $78.53 \%$ and $82.16 \%$ (Figures 2D and 3D). A high inhibitory effect was also proved against S. typhimurium, with BIR\% varying from $68.88 \%$ to $76.65 \%$. The evolution was connected to the tested concentration, as BGR $\%$ ranged from $69.88 \%$ for the concentration $2 \%$ of $\mathrm{TpB}$ up to $76.65 \%$ for $\mathrm{TpC}$ at $16 \%$ concentration. The $2 \mu \mathrm{L} / 100 \mu \mathrm{L}$ concentration proved to be MIC for all the tested microorganisms except for S. aureus, P. aeruginosa and H. influenzae (Table 4).

Against $S$. aureus, $\mathrm{TpB}$ produced a strain boosting effect with BGR\% values of $177.54 \%$ for $\mathrm{TpB} 2 \%$ and $149.31 \%$ for TpB $16 \%$, the BIR\% values being negative. Our results were in agreement with previous studies, which showed that the antimicrobial effect of $\mathrm{EO}$ on T. marschallianus is high on Gram-positive bacteria, except S. aureus [45].

The strain boosting effect was also shown in the case of P. aeruginosa and H. influenzae at $2 \%$ and $4 \%$ concentrations tested. For $P$. aeruginosa, the inhibitory effect had a slower evolution with BIR $\%$ of $6.54 \%$ at $8 \%$ and $24.48 \%$ for $\mathrm{TpB} 16 \%$. Concerning the TpB activity against $H$. influenzae, the effect was shown at $8 \%$ concentration with BGR $\%$ of $66.72 \%$ and $53.41 \%$ in the case of TpB $16 \%$.

Regarding the antifungal activity of $\mathrm{TpB}, \mathrm{C}$. parapsilopsis presented a higher percentage of fungal mass loss compared to C. albicans with MIR\% ranging from $26.38 \%$ to $82.70 \%$. From a different point of view, C. albicans proved to be more inhibited at a lower concentration, with values of MIR $\%$ starting from $58.71 \%$ at $2 \%$ up to $63.66 \%$ for $16 \%$, compared to the values obtained against $C$. parapsilopsis.

To summarize the data regarding the TvL antimicrobial activity presented in Figures $2 \mathrm{E}$ and $3 \mathrm{E}$, we can observe that TvL was most effective against S. flexneri, S. typhimurium and 
S. pyogenes and both fungal strains. Concerning the highest antibacterial activity proved by BIR $\%$, the obtained values, at $16 \%$ concentration, ranged between $64.94 \%$ and $77.32 \%$ (Figure 3E). Regarding the other tested strains, E. coli and H. influenzae, TvL had a proven growth-inhibitory effect, with a BGR compared to control (\%) varying from $39.90 \%$ to $57.72 \%$ for $E$. coli and from $59.82 \%$ to $75.77 \%$ for $H$. influenzae. Our results were in agreement with previous studies [45-47], which showed that T. vulgaris EO has an inhibitory effect, especially on Gram-positive bacteria.

The results were in correlation with the findings presented by Al-Shuneigat et al., which stated inhibitory results for concentrations varying from $0.5 \%$ to $4 \%$ [48].

Concerning MIR\%, the effect was also an inhibitory one, with values varying from $67.32 \%$ to $78.52 \%$ for C. parapsilopsis and $28.82 \%$ to $58.44 \%$ for C. albicans. Our results were in agreement with previous studies [49], which showed a strong antifungal activity of the EO in T. vulgaris and a correlation of this effect with the amount of thymol, $p$-cymene and $\gamma$-terpinol in this oil.

In the case of S. aureus, the inhibitory effect was proved at $8 \%$ with BIR $\%$ of $52.13 \%$, while the lowest concentrations tested proved a growth-boosting effect, with BGR $\%$ values compared to control of $105 \%$. The effect on P. aeruginosa proved to be one of mass growth in close correlation with the concentration, as the BIR\% values started at $35.51 \%$ for $2 \%$ concentration and decreased at $-8.46 \%$ for TvL16\%. This result was inconsistent with Mancini et al. (2015), but because significantly lower concentrations of EO were used, further studies are needed to clarify the dynamics of the antimicrobial effect for this EO [46].

de Carvalho et al. [50] presented, in their study published in 2015, a MIC value of 25 $\mu \mathrm{LEO} / 100 \mu \mathrm{L}$ against $S$. aureus, a value much higher than the one obtained by us (Table 4 ).

Analyzing the complete results of the antibacterial tests, we can conclude that the most affected strains when Thymus sp. EOs were used were S. flexneri, S. typhimurium and S. pyogenes, and regarding the antifungal activity, C. parapsilopsis proved to be more sensitive compared to C. albicans.

Our results were in agreement with previous studies [45,46,51], which showed that Thymus EO has in vitro inhibitory activity against some of the microorganisms tested. Using the MIC method, the lowest inhibitory concentrations were found to be against S. enteritidis, P. aeruginosa and biofilm-forming bacteria. Galovičová et al. (2021) highlighted that the highest inhibitory concentrations of T. serpyllum were identified against $S$. aureus and $C$. tropicalis, and the lowest inhibitory concentrations were found against $S$. enteritidis and $P$. aeruginosa [52]. Earlier studies have demonstrated the antifungal potential of thymol against Candida species, because this interferes with the formation and viability of mycelium hyphae [25,49].

The analysis of correlation between the antimicrobial effect of Thymus species against the analyzed strains and the chemical composition is presented in the Supplementary Materials file 2.

$\mathrm{TgS}$ represents the least studied Thymus species from spontaneous flora, in terms of antimicrobial effects and their correlation with the chemical composition. The results reported in Table 2 highlight an important diversity in terms of the chemical composition of TgS. We noticed a high content of thymol $(30.82 \%)$, but also a significant percentage of $p$-cymene $(8.55 \%)$, carvacrol $(7.94 \%)$ and $\gamma$-terpinene $(8.96 \%)$. The antimicrobial activity of $\mathrm{TgS}$ was the most important, compared to the other samples analyzed, and refers to the preponderant inhibition of S. pyogenes, S. typhimurium and C. parapsilopsis strains. Supplementary Materials file 2 shows that the strongest positive correlations were reported for the mentioned chemical compounds, namely the pairs S. pyogenes / $p$-cymene $(\mathrm{r}=0.904)$ and $\gamma$-terpinene $(\mathrm{r}=0.852)$; $S$. typhimurium and carvacrol $(\mathrm{r}=0.999)$, thymol $(\mathrm{r}=0.716)$, $p$-cymene $(r=0.982)$ and $\gamma$-terpinene $(r=0.997)$; and C. parapsilopsis / carvacrol $(r=0.957)$, $p$-cymene $(\mathrm{r}=0.866) \gamma$-terpinene $(\mathrm{r}=0.916)$ and thymol $(\mathrm{r}=0.905)$, which confirms that some minor compounds, or the association of minor compounds with major compounds in 
the EO's composition leads to strong antimicrobial effects as fewer individual compounds, even if they are found in large quantities.

In this regard, Mancini et al. (2015) highlighted that minor components have a critical part to play in antibacterial activity, possibly by producing a synergistic effect between other components [46]. Ahmad and coworkers (2014), reported that synergistic and additive interactions occur between the major and minor constituents present in the EO of Thymus and, in this way, the antimicrobial efficacy could be enhanced [51].

Additionally, Guimarães et al. (2019) stated that the classification of the antimicrobial actions of pure compounds is not well consolidated in the literature, making difficult the comparison with previous results. They proved that thymol had a positive effect on Salmonella sp., E. coli and S. aureus, and that oxygenated functional groups in terpene compounds exhibited better antimicrobial activity than hydrocarbons [53].

The correlation data of TpP presented in Supplementary Materials file (Table S1) are in agreement with the results regarding the chemical composition (Table 2) and the antimicrobial effects (Figures 2B and 3B). TpP is characterized by an important content of $p$-cymene $(15.12 \%)$ and cis-geraniol $(1.88 \%)$, in addition to thymol, which is the major compound in all Thymus species analyzed (Table 2), as well as high inhibitory effects on the development of stem cells S. flexneri, S. pyogenes, S. typhimurium and C. parapsilopsis (Figures 2B and 3B). The existence of a strongly positive correlation between $S$. pyogenes and $p$-cymene $(\mathrm{r}=0.925)$, S. flexneri and $p$-cymene $(\mathrm{r}=0.989)$, S. typhimurium and cis-geraniol $(\mathrm{r}=0.945)$ leads to the conclusion that the synergism generated by the association of $p$-cymene with cis-gernaiol could be responsible for the antibacterial activity on the mentioned strains and not necessarily the presence of thymol, which registers negative correlations with bacterial strains. Marchese et al. (2014) stated that $p$-cymene, a major compound, exerted good antibacterial activity against $S$. pyogenes and methicillin-resistant $S$. aureus (MRSA) and also presented the possibility that $p$-cymene can enhance the inhibitory effects of carvacrol when the two compounds are used together [54].

The nature of strains could be responsible for synergistic or antagonistic effects. Synergistic interactions were mostly observed with Gram-positive microorganisms, while yeasts and Gram-negative strains showed weak synergistic interactions [51].

Regarding the antifungal activity associated with C. parapsilopsis strains, it seems to be associated with oxygenated terpenes, such as cis-geraniol $(r=0.945)$. In this regard, the results reported by Sokovic et al. (2009), regarding the investigation of antifungal properties of Thymus sp., showed that hydrocarbon monoterpenes had the lowest antifungal activity, and a larger antifungal potential could be due to the presence of oxygenated terpenes or of those with phenolic structures [49].

The analysis of correlations between the antimicrobial effects of TpC against the analyzed strains and the chemical compositions highlighted that strong $(\mathrm{r}>0.7)$ positive correlations were recorded between pairs, suggesting possible antimicrobial activity generated by these chemical components: S. pyogenes and carvacrol $(\mathrm{r}=0.999)$ and cis-geraniol $(\mathrm{r}=0.800)$; S. aureus and $p$-cymene $(\mathrm{r}=0.866)$ and cis-geraniol $(\mathrm{r}=0.741)$; S. flexneri and $p$-cymene $(\mathrm{r}=1.000)$ and cis-geraniol $(\mathrm{r}=0.977) ;$ E. coli and carvacrol $(\mathrm{r}=0.997)$ and cis-geraniol $(\mathrm{r}=0.821)$; S. typhimurium and carvacrol $(\mathrm{r}=0.784)$; H. influenzae and carvacrol $(\mathrm{r}=0.976), p$-cymene $(\mathrm{r}=0.778)$ and cis-geraniol $(\mathrm{r}=0.893)$; and C. parapsilopsis and $p$-cymene $(\mathrm{r}=0.756)$.

Togashi et al. (2008) discussed the antibacterial activity and the mode of action of farnesol against $S$. aureus, when geraniol was added to a bacterial suspension. The authors assumed that geraniol increased the growth-inhibitory activity of farnesol. Their results revealed that terpenes might interact with each other and with bacterial cells to increase or decrease the antibacterial activity of each other [55].

Another study highlighted that geraniol significantly increased the efficacy of chloramphenicol by targeting efflux mechanisms and produced a significant restoration of susceptibility of the multidrug resistance strains tested [56]. 
In the case of $\mathrm{TpC}$, a greater number of positive correlations were observed between the chemical composition and the antimicrobial activity. In addition to the associations mentioned in the case of the other EOs analyzed, there was a positive correlation of E. coli and carvacrol $(\mathrm{r}=0.997)$ and cis-geraniol $(\mathrm{r}=0.821)$. TpC represented the sample with the highest percentage of carvacrol $(25.43 \%), 13.12 \%$ cis-geraniol and a high $E$. coli inhibition rate $(68.78 \%)$, which suggest a possible association of the antibacterial effect on E. coli with the presence of the mentioned chemical compounds. Other studies have associated E. coli inhibition with the chemical composition of Thymus EO [51]. Ahmad et al. (2014) suggested that the monoterpene phenols, thymol and carvacrol, were found to be the most active constituents against E. coli, while linalool were generally found to have moderate activity, and $p$-cymene, borneol, $\alpha$-terpinene and $\gamma$-terpinene exhibited weak antimicrobial activity [51].

The correlation analysis of $\mathrm{TpB}$ indicates a possible antibacterial effect against $E$. coli generated by the synergism achieved by associating several chemical components such as carvacrol $(\mathrm{r}=0.995)$, thymol $(\mathrm{r}=1.000), \gamma$-terpinene $(0.924)$, cis-geraniol $(\mathrm{r}=0.995)$ and linalool $(r=0.901)$.

TvL is the most studied species in terms of antimicrobial effects and association with chemical composition. Thymol is the major chemical compound (40.85\%) of the EO and defines the biologically active behavior of TvL. The analysis of correlation data shows that thymol correlated positively with $S$. flexneri and $S$. aureus $(\mathrm{r}=0.771)$. Other authors reported the antimicrobial, antibiofilm and biochemical properties of Thymus EO against clinical isolates of opportunistic infections [57,58].

The analysis of correlation between the antimicrobial effect of TvL against analyzed strains and the chemical composition proved a moderate $(r>0.5)$ positive correlation between C. albicans and carvacrol $(\mathrm{r}=0.663)$.

Other strong $(r>0.7)$ positive correlations were recorded between pairs, suggesting possible antimicrobial activity generated by these chemical components: S. aureus and thymol $(\mathrm{r}=0.771)$; S. flexneri and thymol $(\mathrm{r}=0.771) ;$ E. coli and thymol $(\mathrm{r}=0.817)$; C. parapsilopsis and $p$-cymene $(0.945)$ and $\gamma$-terpinene $(r=0.938)$; and $C$. albicans and $p$-cymene $(0.756)$ and $\gamma$-terpinene $(\mathrm{r}=0.770)$. The cumulative correlation data for all Thymus species studied indicate that for the same chemical compound and the same microbial strain, the correlation between the parameters may be different, depending on the studied species. This fact confirms what was noticed by other authors [51], namely that the complexity of the chemical composition and especially the minor components can generate synergistic or antagonistic effects, so that in complex biological systems a mathematical prediction is difficult to achieve.

The different antimicrobial activities of these oils might be due to the small variation in their chemical profile. It was reported in the literature that various chemical compounds have direct activity against many species of bacteria, such as terpenes and a variety of aliphatic hydrocarbons (alcohols, aldehydes and ketones). The lipophilic character of their hydrocarbon skeleton and the hydrophilic character of their functional groups are of main importance in the antimicrobial action of the components of EOs, and the importance of the hydroxyl group of phenolic structures has been confirmed [51].

To conclude the correlation study, we can state that the chemical compounds found in the EOs extracted from Thymus sp. are responsible for the antimicrobial activity, the existing correlations being influenced by the synergism/antagonism exerted between the compounds and the morphological characteristics of the strains (Gram-positive, Gramnegative and fungi).

\section{Materials and Methods}

\subsection{Plant Material}

The species analyzed in the present study are presented in Table 5. T. odoratissimus Mill. (syn T. glabrescens Willd.), collected around the settlement of Silagiu (code: TgS), T. pulegioides L., collected around the settlement of Prigor, (code: TpP), T. pulegioides L., 
collected around Carasova (code: TpC), T. pulegioides L., collected around Bazias (code: TpB) and T. vulgaris L., cultivated and collected from the Agricultural Research and Development Station Lovrin (code: TvL).

Table 5. Species of the genus Thymus analyzed and their location.

\begin{tabular}{|c|c|c|c|c|c|c|c|}
\hline \multirow{2}{*}{ Code } & \multirow{2}{*}{ Analyzed Species } & \multirow{2}{*}{ Location } & \multirow{2}{*}{$\begin{array}{c}\text { Voucher Specimen } \\
\text { Number }\end{array}$} & \multirow{2}{*}{ County } & \multicolumn{3}{|c|}{ GPS Coordinates (Decimal Degree) } \\
\hline & & & & & Altitude (m) & Latitude & Longitude \\
\hline $\operatorname{TgS}$ & Thymus odoratissimus Mill. & Silagiu & VSNH.BUASTM: 1931 & Timis & 192 & 45.60703 & 21.60335 \\
\hline TgP & Thymus pulegioides L. & Prigor & VSNH.BUASTM: 1934 & Caras-Severin & 347 & 44.932547 & 22.115320 \\
\hline $\operatorname{TgC}$ & Thymus pulegioides L. & Carasova & VSNH.BUASTM: 1932 & Caras-Severin & 568 & 45.152790 & 21.878892 \\
\hline $\operatorname{TgB}$ & Thymus pulegioides L. & Bazias & VSNH.BUASTM: 1933 & Caras-Severin & 120 & 44.823742 & 21.387344 \\
\hline TvL & Thymus vulgaris L. & Lovrin & VSNH.BUASTM: 1927 & Timis & 91 & 45.975270 & 20.789621 \\
\hline
\end{tabular}

The analyzed Thymus populations were harvested during flowering, from five different habitats in Banat, Romania, in 2019 (T. pulegioides, T. vulgaris) and 2020 (T. odoratissimus). These were studied in the laboratory to establish the species accurately. The determination was made with the help of specialized determinants [7,8], and the scientific names were updated after The EuroPlusMedPlantbase (electronic edition) [9]. Species were determined using morphological criteria described in the literature [3].

Sample vouchers for each population were stored after identification in the herbarium of the Crop Science Department within the University of Agricultural Sciences and Veterinary Medicine of Banat "King Mihai I of Romania" from Timisoara.

\subsection{Obtaining the EOs}

The EOs analyzed in the present paper were obtained from mixtures of subspecies (10-20) of the same species belonging to the genus Thymus, from a collection area. Therefore, oils with different characteristics were obtained from the five collection areas. The extraction of EOs was carried out from the dried aerial parts of thyme plant, using hydrodistillation equipment (Clevenger extractor, experimental model, Timisoara, Romania). The resulting $\mathrm{EO}$ and aromatic water mixture were separated using a separating funnel. The pure EOs were stored in glass vials at $+4{ }^{\circ} \mathrm{C}$ until further analysis. The extraction yield was calculated as a percentage of dried plant herba.

\subsection{GC-MS Analysis of EOs}

The chemical constituents of EOs isolated from the aerial part of Thymus sp. were determined by using a gas chromatograph (Shimadzu 2010, Kyoto, Japan) coupled with a triple quadrupole mass spectrometer (TQ 8040, Shimadzu, Kyoto, Japan). The used column was an optima 1MS + WAX column $(30 \mathrm{~m} \times 0.25 \mathrm{~mm}$ i.d., $0.25 \mu \mathrm{m}$ film thickness, Macherey-Nagel, Duren, Germany) using helium as carrier gas at $1 \mathrm{~mL} \mathrm{~min}^{-1} \mathrm{flow}$. The oven temperature was initiated at $+70{ }^{\circ} \mathrm{C}$ for $11 \mathrm{~min}$ and raised to $+190{ }^{\circ} \mathrm{C}$ at a rate of $5{ }^{\circ} \mathrm{C} \mathrm{min}-1$ and then to $+240{ }^{\circ} \mathrm{C}$ at a rate of $+20^{\circ} \mathrm{C} \mathrm{min}^{-1}$, where it was kept for $5 \mathrm{~min}$. Injector and MS source temperatures were set to $+250^{\circ} \mathrm{C}$ and $+200^{\circ} \mathrm{C}$, respectively. The samples were diluted before injection $(1: 25, \mathrm{v}: \mathrm{v})$, and the injection volume was $1 \mu \mathrm{L}$, with a split ratio of 10:1.

The EO constituents were identified based on the comparison of their retention indices (abbreviated $\mathrm{RI}^{\mathrm{a}}$ ), determined relative to the $t_{R}$ values of $n$-alkanes $(\mathrm{C} 10-\mathrm{C} 35)$ on both capillary columns with those in the literature [59] and their mass spectra with those of standard compounds ( $\alpha$-pinene; sabinene; $\beta$-pinene; $\beta$-myrcene; $\alpha$-phellandrene; 3 -carene; D-limonene; cis- $\beta$-ocimene; trans- $\beta$-ocimene; carvacrol; caryophyllene) available in our laboratories or those listed in the NIST 14 and Wiley 09 mass spectral libraries (abbreviated RI ${ }^{\mathrm{b}}$ ). 


\subsection{Determination of Antimicrobial Activity}

The microbial strains used in this study were obtained from the culture collection of the Microbiology Laboratory of the Interdisciplinary Research Platform within the University of Agricultural Sciences and Veterinary Medicine "King Mihai I of Romania" in Banat, Timisoara. In our laboratory, ATCC strains are maintained at $-50{ }^{\circ} \mathrm{C}$.

The EOs were tested against S. aureus (ATCC 25923), S. pyogenes (ATCC 19615), E. coli (ATCC 25922), P. aeruginosa (ATCC 27853), S. flexneri (ATCC 12022), S. typhimurium (ATCC 14028), H. influenzae type B (ATCC 10211), C. albicans (ATCC 10231) and C. parapsilopsis (ATCC 22019).

The MIC is defined as the lowest compound concentration that yields no visible microorganism growth. The method of MIC determination based on the microbial mass loss by measurement of OD by spectrophotometry according to ISO 20776-1:2019 was described in our previous research [60].

\subsubsection{Bacterial Culture}

A $10^{-3}$ dilution of the fresh culture was used to perform the assay, an inoculum equivalent to a $0.5 \mathrm{McF}$ arland standard. The ATCC strains were revived by overnight growth in Brain Heart Infusion (BHI) broth CM1135 (Oxoid, Hampshire, UK) at $37^{\circ} \mathrm{C}$ and subsequently passed on BHI agar (Oxoid, CM1136) for $24 \mathrm{~h}$ at $37^{\circ} \mathrm{C}$. The cultures were then diluted at an optical density (OD) of $0.5 \mathrm{McF}$ arland standard $\left(1.5 \times 10^{8} \mathrm{UFC} \times \mathrm{mL}\right)$ using BHI broth and a McFarland densitometer Grand-Bio (Fisher Scientific, Loughborough, UK). The suspensions were tested using a 96 microdilution well plate. Using a Calibra digital 852 multichannel pipette, $100 \mu \mathrm{L}$ of microbial suspension was placed in each well. The EOs were tested at a concentration of $2 \%, 4 \%, 8 \%$ and $16 \%$, added in each well. The plates were covered and left $24 \mathrm{~h}$ at $37^{\circ} \mathrm{C}$. After $24 \mathrm{~h}$, the OD was measured at $540 \mathrm{~nm}$ using an ELISA reader (BIORAD PR 1100, Hercules, CA, USA). Triplicate tests were performed for all samples. The suspensions of strain and BHI were used as a negative control.

To interpret the results, two indicators were calculated, namely BGR and BIR, by using the following formulas:

$$
\begin{gathered}
\mathrm{BGR}=\frac{\mathrm{OD}_{\text {sample }}}{\mathrm{OD}_{\text {negative }} \text { control }} \times 100 \quad(\%) \\
\mathrm{BIR}=100-\mathrm{BGR}(\%)
\end{gathered}
$$

where OD sample-optical density at $540 \mathrm{~nm}$ as the mean value of triplicate readings for EOs in the presence of the selected bacteria; OD negative control—optical density at $540 \mathrm{~nm}$ as the mean value of triplicate readings for the selected bacteria in BHI.

BGR/MGR indicators are calculated values expressed as percentages of growth or inhibition, indicators used previously in several other research articles [56,60-62].

\subsubsection{Fungi Culture}

A $10^{-2}$ dilution of the fresh culture was used to perform the assay, an inoculum equivalent to a $0.5 \mathrm{McF}$ arland standard. The ATCC fungal strains were revived by overnight growth in Brain Heart Infusion (BHI) broth CM1135, (Oxoid, Hampshire, UK) at $37^{\circ} \mathrm{C}$ and subsequently passed on BHI agar (Oxoid, CM1136) for $48 \mathrm{~h}$ at $37^{\circ} \mathrm{C}$. The cultures were then diluted at an OD of 0.5 McFarland standard using BHI broth, a value determined by using a McFarland densitometer Grand-Bio (Fisher Scientific, Loughborough, UK). The suspensions were tested using a 96 microdilution well plate by placing $100 \mu \mathrm{L}$ of microbial suspension in each well. The EOs were tested at a concentration of $2 \%, 4 \%, 8 \%$ and $16 \%$, added in each well. The plates were covered and left for $48 \mathrm{~h}$ at $37^{\circ} \mathrm{C}$. After $48 \mathrm{~h}$, the OD was measured at $540 \mathrm{~nm}$. Triplicate tests were performed for all samples. 
To interpret the results, two indicators were calculated, namely MGR and MIR, using the following formulas:

$$
\begin{gathered}
\text { MGR }=\frac{\mathrm{OD}_{\text {sample }}}{\mathrm{OD}_{\text {negative }} \text { control }} \times 100 \quad(\%) \\
\text { MIR }=100-\operatorname{MGR~}(\%)
\end{gathered}
$$

where OD sample-optical density at $540 \mathrm{~nm}$ as the mean value of triplicate readings for EOs in presence of the selected fungi; OD negative control-optical density at $540 \mathrm{~nm}$ as the mean value of triplicate readings for the selected fungi in BHI.

\subsection{Statistical Analysis}

All determinations were made in triplicate, and the results are reported as mean values \pm standard deviation (SD). These were calculated using GraphPad Prism (v.5.0 software, San Diego, CA, USA). The differences between means were analyzed with a one-way ANOVA, followed by a multiple comparison analysis using the $t$-test (twosample assuming equal variances). The differences were considered significant when $p$-values $<0.05$. Correlations between variables were performed using Microsoft Excel 2013.

\section{Conclusions}

The results reported here may help to shed light on the complex chemotaxonomy of the genus Thymus. There is a significant relationship between the antimicrobial activity of Thymus EOs and the presence of phenolic compounds, such as thymol and carvacrol. The correlation study highlighted that the chemical compounds of the Thymus sp. EOs are responsible for the antimicrobial activity, the existing correlations being influenced by the synergism/antagonism exerted between the compounds and the morphological characteristics of the strains (Gram-positive, Gram-negative and fungi).

Regarding the general results of the study, the studied EOs from Thymus sp. can find practical uses in preventing bacterial or fungal infections in plants, animals or humans, being $100 \%$ natural and non-toxic in small amounts.

On the other hand, significant variations in the chemical profile identified in T. pulegiodes collected from different locations in Western Romania may indicate a high level of biodiversity in this species, and further investigations in terms of polymorphism, chemical and antimicrobial potential may be useful. The identified antimicrobial activity of these oils could be the way to discover new natural preservation modalities with possible uses in the food and cosmetics industry, replacing synthetic preservatives, compounds that present a higher degree of toxicity to humans and animals.

Supplementary Materials: The following are available online at https:/ /www.mdpi.com/article/10 .3390 / plants10091833/s1, Supplementary Materials Figure S1: The individual chromatograms of Thymus EOs, Supplementary materials Table S2: The analysis of correlation between the antimicrobial effect of Thymus species against the analyzed strains and the chemical composition.

Author Contributions: Conceptualization, R.B. and I.M.I.; methodology, R.B., E.A., D.O., I.C., G.P., F.I., D.C., C.M., A.L., L.C., D.M.C. and I.M.I.; validation, R.B., E.A., D.O. and I.M.I.; formal analysis, R.B., E.A., D.O., I.C., G.P., F.I., D.C., C.M., A.L., L.C., D.M.C. and I.M.I.; investigation, R.B., E.A., D.O., I.C., G.P., F.I., D.C., C.M., A.L., L.C., D.M.C. and I.M.I.; resources, R.B., E.A., D.O., I.C., G.P., F.I. and I.M.I.; data curation, R.B., E.A., D.O., I.C. and I.M.I.; writing-original draft preparation, R.B., E.A., D.O., I.C., G.P., F.I., D.C., C.M., A.L., L.C., D.M.C. and I.M.I.; writing-review and editing, R.B., E.A., D.O., I.C. and I.M.I.; visualization, R.B., E.A., D.O., I.C., G.P., F.I., D.C., C.M., A.L., L.C., D.M.C. and I.M.I.; supervision, R.B., E.A., D.O. and I.M.I. All authors have read and agreed to the published version of the manuscript. 
Funding: This research was published from internal funds of the Banat's University of Agricultural Sciences and Veterinary Medicine "King Michael I of România" from Timișoara. A part of this work was supported by a grant from the Romanian Ministry of Education and Research, CNCS-UEFISCDI, project number PN-III-P1-1.1-PD-2019-0349, within PNCDI III.

Institutional Review Board Statement: Ethical review and approval were waived for this study because this article does not contain any studies with human or animal subjects.

Data Availability Statement: Data supporting reported results can be found at Interdisciplinary Research Platform within the Banat University of Agricultural Sciences and Veterinary Medicine "King Mihai I of Romania", Timisoara, Romania and at Institute for Research, Development and Innovation in Technical and Natural Sciences, Aurel Vlaicu University, Arad, Romania.

Acknowledgments: The microbiological work was provided by the Microbiology Laboratory of the Interdisciplinary Research Platform within the Banat University of Agricultural Sciences and Veterinary Medicine "King Mihai I of Romania", Timisoara.

Conflicts of Interest: The authors declare no conflict of interest.

\section{References}

1. Rustaiee, A.; Sefidkon, F.; Tabatabaei, S.M.F.; Omidbaigi, R.; Mirahmadi, S.F.; Shayganfar, A. Chemical Polymorphism of Essential Oils from Five Populations of Thymus daenensis Celak. subsp. daenensis Endemic to Iran. J. Essent. Oil Res. 2011, $23,6-11$. [CrossRef]

2. Pluhár, Z.; Kocsis, M.; Kuczmog, A.; Csete, S.; Simkó, H.; Sárosi, S.; Molnar, P.; Horváth, G. Essential oil composition and preliminary molecular study of four Hungarian Thymus species. Acta Biol. Hung. 2012, 63, 81-96. [CrossRef]

3. Morales, R. The history, botany and taxonomy of the genus Thymus. In Thyme: The Genus Thymus, 1st ed.; Stahl-Biskup, E., Saez, F., Eds.; Taylor and Francis: London, UK, 2002; pp. 1-43.

4. Ložienè, K.; Venskutonis, P. Influence of environmental and genetic factors on the stability of essential oil composition of Thymus pulegioides. Biochem. Syst. Ecol. 2005, 33, 517-525. [CrossRef]

5. Taghouti, M.; Martins-Gomes, C.; Félix, L.M.; Schäfer, J.; Santos, J.A.; Bunzel, M.; Nunes, F.M.; Silva, A.M. Polyphenol composition and biological activity of Thymus citriodorus and Thymus vulgaris: Comparison with endemic Iberian Thymus species. Food Chem. 2020, 331, 127362. [CrossRef]

6. Gușuleac, M. Thymus L. In Flora Romaniae; Săvulescu, T.R., Redactore Tomi Nyarady, E.I., Beldie, A., Bioa, A., Grințescu, I., Gușuleac, M., Moraiu, I., Nyarady, A., Nyarady, E.I., Paucă, A., et al., Eds.; Academia Română Publishing House: Bucharest, Romania, 1961; pp. 301-334.

7. Sârbu, I.; Ștefan, N.; Oprea, A. Plante Vasculare din România. Determinator Ilustrat de Teren; Victor B Victor: Bucharest, Romania, 2013; pp. 666-674. ISBN 9786068149080.

8. The EuroPlusMedPlantbase. Available online: https://ww2.bgbm.org/EuroPlusMed/query.asp (accessed on 23 June 2021).

9. Ramchoun, M.; Khouya, T.; Harnafi, H.; Amrani, S.; Alem, C.; Benlyas, M.; Chadli, F.K.; Nazih, H.; Nguyen, P.; Ouguerram, K. Effect of Aqueous Extract and Polyphenol Fraction Derived from Thymus atlanticus Leaves on Acute Hyperlipidemia in the Syrian Golden Hamsters. Evid.-Based Complement. Altern. Med. 2020, 2020, 1-9. [CrossRef]

10. Hoven, R.V.D.; Zappe, H.; Zitterl-Eglseer, K.; Jugl, M.; Franz, C. Study of the effect of Bronchipret on the lung function of five Austrian saddle horses suffering recurrent airway obstruction (heaves). Veter. Rec. 2003, 152, 555-557. [CrossRef] [PubMed]

11. Nascimento, G.G.F.; Locatelli, J.; Freitas, P.C.; Silva, G.L. Antibacterial activity of plant extracts and phytochemicals on antibioticresistant bacteria. Braz. J. Microbiol. 2000, 31, 247-256. [CrossRef]

12. Ciobotaru, V.G.G.; Pavel, I.Z.; Borcan, F.; Moaca, A.; Danciu, C.; Diaconeasa, Z.; Imbrea, I.; Vlad, D.; Dumitrascu, V.; Pop, G. Toxicological Evaluation of Some Essential Oils Obtained from Selected Romania Lamiaceae Species in Complex with Hydroxypropyl-Gamma-cyclodextrin. Rev. Chim. 2019, 70, 3703-3707. [CrossRef]

13. Alexa, E.; Sumalan, R.M.; Danciu, C.; Obistioiu, D.; Negrea, M.; Poiana, M.-A.; Rus, C.; Radulov, I.; Pop, G.; Dehelean, C. Synergistic Antifungal, Allelopatic and Anti-Proliferative Potential of Salvia officinalis L., and Thymus vulgaris L. Essential Oils. Molecules 2018, 23, 185. [CrossRef]

14. Granger, R.; Passet, J. Thymus vulgaris spontane de France: Races chimiques et chemotaxonomie. Phytochemistry 1973, 12, 1683-1691. [CrossRef]

15. Semeniuc, C.A.; Socaciu, M.-I.; Socaci, S.A.; Mureșan, V.; Nagy, M.; Rotar, A.M. Chemometric Comparison and Classification of Some Essential Oils Extracted from Plants Belonging to Apiaceae and Lamiaceae Families Based on Their Chemical Composition and Biological Activities. Molecules 2018, 23, 2261. [CrossRef]

16. Pinto, E.; Gonçalves, M.J.; Hrimpeng, K.; Pinto, J.; Vaz, S.; Vale-Silva, L.A.; Cavaleiro, C.; Salgueiro, L. Antifungal activity of the essential oil of Thymus villosus subsp. lusitanicus against Candida, Cryptococcus, Aspergillus and dermatophyte species. Ind. Crop. Prod. 2013, 51, 93-99. [CrossRef]

17. Lawrence, B.M.; Tucker, A.O. The genus Thymus as a source of commercial products. In Thyme: The Genus Thymus, 1st ed.; Stahl-Biskup, E., Saez, F., Eds.; Taylor and Francis: London, UK, 2002; p. 330. 
18. Hadian, J.; Bigdeloo, M.; Nazeri, V.; Khadivi-Khub, A. Assessment of genetic and chemical variability in Thymus caramanicus. Mol. Biol. Rep. 2014, 41, 3201-3210. [CrossRef] [PubMed]

19. Tohidi, B.; Rahimmalek, M.; Arzani, A.; Sabzalian, M.R. Thymol, carvacrol, and antioxidant accumulation in Thymus species in response to different light spectra emitted by light-emitting diodes. Food Chem. 2020, 307, 125521. [CrossRef]

20. Ghasemi, P.; Barani, M.; Hamedi, B.; Ataei, K.; Karimi, A. Environment effect on diversity in quality and quantity of essential oil of different wild populations of Kerman thyme. Genetika 2013, 45, 441-450. [CrossRef]

21. Vladimir-Knežević, S.; Blažeković, B.; Kindl, M.; Vladić, J.; Lower-Nedza, A.D.; Brantner, A.H. Acetylcholinesterase Inhibitory, Antioxidant and Phytochemical Properties of Selected Medicinal Plants of the Lamiaceae Family. Molecules 2014, 19, 767-782. [CrossRef] [PubMed]

22. Cocan, I.; Alexa, E.; Danciu, C.; Radulov, I.; Galuscan, A.; Obistioiu, D.; Morvay, A.A.; Sumalan, R.M.; Poiana, M.-A.; Pop, G.; et al. Phytochemical screening and biological activity of Lamiaceae family plant extracts. Exp. Ther. Med. 2017, 15, 1863-1870. [CrossRef]

23. Nieto, G. Biological Activities of Three Essential Oils of the Lamiaceae Family. Medicines 2017, 4, 63. [CrossRef]

24. Karpiński, T.M. Essential Oils of Lamiaceae Family Plants as Antifungals. Biomolecules 2020, 10, 103. [CrossRef] [PubMed]

25. Iseppi, R.; Tardugno, R.; Brighenti, V.; Benvenuti, S.; Sabia, C.; Pellati, F.; Messi, P. Phytochemical Composition and In Vitro Antimicrobial Activity of Essential Oils from the Lamiaceae Family against Streptococcus agalactiae and Candida albicans Biofilms. Antibiotics 2020, 9, 592. [CrossRef]

26. Ložienė, K.; Vaičiulytè, V.; Maždžierienė, R. Influence of meteorological conditions on essential oil composition in geraniol-bearing Thymus pulegioides and Thymus hybrid. Acta Physiol. Plant. 2021, 43, 1-9. [CrossRef]

27. Imelouane, B.; Amhamdi, H.; Wathelet, J.P.; Ankit, M.; Khedid, K.; El Bachiri, A. Chemical composition and antimicrobial activity of essential oil of thyme (Thymus vulgaris) from Eastern Morocco. Int. J. Agric. Biol. 2009, 11, 205-208.

28. Golkar, P.; Mosavat, N.; Jalali, S.A.H. Essential oils, chemical constituents, antioxidant, antibacterial and in vitro cytotoxic activity of different Thymus species and Zataria multiflora collected from Iran. S. Afr. J. Bot. 2020, 130, 250-258. [CrossRef]

29. Pavel, M.; Ristić, M.; Stević, T. Essential oils of Thymus pulegioides and Thymus glabrescens from Romania: Chemical composition and antimicrobial activity. J. Serb. Chem. Soc. 2010, 75, 27-34. [CrossRef]

30. Mamadalieva, N.Z.; Akramov, D.K.; Ovidi, E.; Tiezzi, A.; Nahar, L.; Azimova, S.S.; Sarker, S.D. Aromatic Medicinal Plants of the Lamiaceae Family from Uzbekistan: Ethnopharmacology, Essential Oils Composition, and Biological Activities. Medicines 2017, 4, 8. [CrossRef] [PubMed]

31. Boros, B.; Jakabová, S.; Dornyei, A.; Horváth, G.; Pluhár, Z.; Kilar, F.; Felinger, A. Determination of polyphenolic compounds by liquid chromatography-mass spectrometry in Thymus species. J. Chromatogr. A 2010, 1217, 7972-7980. [CrossRef]

32. Borugă, O.; Jianu, C.; Mişcă, C.; Goleț, I.; Gruia, A.T.; Horhat, F.G. Thymus vulgaris essential oil: Chemical composition nd antimicrobial activity. J. Med. Life 2014, 7, 56-60.

33. Isopencu, G.; Ferdes, M. Aspects regarding the influence of concentration of compoments with antifungal activity from some essential oils. Rev. Chim. 2012, 63, 205-211.

34. Grigore, A.; Mihul, A.; Paraschiv, I.; Nita, S.; Christof, R.; Iuksel, R.; Ichim, M. Chemical analysis and antimicrobial activity of indigenous medicinal species volatile oils. Rom. Biotechnol. Lett. 2012, 17, 7620-7627.

35. Varga, E.; Bardocz, A.; Belak, A.; Maraz, A.; Boros, B.; Felinger, A.; Boszormenyi, A.; Horvath, G. Antimicrobial activity and chemical composition of thyme essential oils and the polyphenolic content of different Thymus extract. Farmacia 2015, 63, 357-361.

36. Lorenzo, J.M.; Munekata, P.E.S.; Dominguez, R.; Pateiro, M.; Saraiva, J.A.; Franco, D. Main Groups of Microorganisms of Relevance for Food Safety and Stability. Innov. Technol. Food Preserv. 2018, 2018, 53-107. [CrossRef]

37. Park, S.-N.; Lim, Y.K.; Freire, M.; Cho, E.; Jin, D.; Kook, J.-K. Antimicrobial effect of linalool and $\alpha$-terpineol against periodontopathic and cariogenic bacteria. Anaerobe 2012, 18, 369-372. [CrossRef] [PubMed]

38. Rehab, M.A.E.-B.; Zeinab, S.H. Eugenol and linalool: Comparison of their antibacterial and antifungal activities. Afr. J. Microbiol. Res. 2016, 10, 1860-1872. [CrossRef]

39. Ložienè, K.; Venskutonis, P.R.; Šipailienè, A.; Labokas, J. Radical scavenging and antibacterial properties of the extracts from different Thymus pulegioides L. chemotypes. Food Chem. 2007, 103, 546-559. [CrossRef]

40. Mockute, D.; Bernotiene, G. Five Chemotypes of the Essential Oils of Thymus pulegioides L. Growing Wild in Lithuania. J. Essent. Oil Bear. Plants 2003, 6, 139-147. [CrossRef]

41. De Martino, L.; Bruno, M.; Formisano, C.; De Feo, V.; Napolitano, F.; Rosselli, S.; Senatore, F. Chemical Composition and Antimicrobial Activity of the Essential Oils from Two Species of Thymus Growing Wild in Southern Italy. Molecules 2009, 14, 4614-4624. [CrossRef]

42. Duman, A.D.; Telci, I.; Dayisoylu, K.S.; Digrak, M.; Demirtas, I.; Alma, M.H. Evaluation of Bioactivity of Linalool-rich Essential Oils from Ocimum basilucum and Coriandrum sativum Varieties. Nat. Prod. Commun. 2010, 5, 969-974. [CrossRef]

43. Afonso, A.F.; Pereira, O.R.; Válega, M.; Silva, A.M.S.; Cardoso, S.M. Metabolites and Biological Activities of Thymus zygis, Thymus pulegioides, and Thymus fragrantissimus Grown under Organic Cultivation. Molecules 2018, 23, 1514. [CrossRef]

44. Vaičiulytė, V.; Ložienė, K.; Švedienè, J.; Raudonienè, V.; Paškevičius, A. $\alpha$-Terpinyl Acetate: Occurrence in Essential Oils Bearing Thymus pulegioides, Phytotoxicity, and Antimicrobial Effects. Molecules 2021, 26, 1065. [CrossRef] 
45. Niculae, M.; Hanganu, D.; Oniga, I.; Benedec, D.; Ielciu, I.; Giupana, R.; Sandru, C.D.; Ciocârlan, N.; Spinu, M. Phytochemical Profile and Antimicrobial Potential of Extracts Obtained from Thymus marschallianus Willd. Molecules 2019, 24, 3101. [CrossRef] [PubMed]

46. Mancini, E.; Senatore, F.; Del Monte, D.; De Martino, L.; Grulova, D.; Scognamiglio, M.; Snoussi, M.; De Feo, V. Studies on Chemical Composition, Antimicrobial and Antioxidant Activities of Five Thymus vulgaris L. Essential Oils. Molecules 2015, 20, 12016-12028. [CrossRef]

47. Verma, R.S.; Padalia, R.C.; Saikia, D.; Chauhan, A.; Krishna, V.; Sundaresan, V. Chemical Composition and Antimicrobial Activity of the Essential Oils Isolated from the Herbage and Aqueous Distillates of two Thymus Species. J. Essent. Oil Bear. Plants 2016, 19, 936-943. [CrossRef]

48. Al-Shuneigat, J.; Al-Sarayreh, S.; Al-Saraireh, Y.; Al-Qudah, M.; Al-Tarawneh, I.; Al Bataineh, E. Effects of wild Thymus vulgaris essential oil on clinical isolates biofilm-forming bacteria. IOSR J. Dent. Med Sci. 2014, 13, 62-66. [CrossRef]

49. Soković, M.D.; Vukojevic, J.; Marin, P.D.; Brkić, D.D.; Vajs, V.; Van Griensven, L.J.L.D. Chemical Composition of Essential Oilsof Thymus and Mentha Speciesand Their Antifungal Activities. Molecules 2009, 14, 238-249. [CrossRef]

50. De Carvalho, R.J.; de Souza, G.T.; Honório, V.G.; de Sousa, J.P.; da Conceição, M.L.; Maganani, M.; de Souza, E.L. Comparative inhibitory effects of Thymus vulgaris L. essential oil against Staphylococcus aureus, Listeria monocytogenes and mesophilic starter co-culture in cheese-mimicking models. Food Microbiol. 2015, 52, 59-65. [CrossRef]

51. Ahmad, A.; Van Vuuren, S.; Viljoen, A. Unravelling the Complex Antimicrobial Interactions of Essential Oils-The Case of Thymus vulgaris (Thyme). Molecules 2014, 19, 2896-2910. [CrossRef] [PubMed]

52. Galovičová, L.; Borotová, P.; Valková, V.; Vukovic, N.; Vukic, M.; Terentjeva, M.; Štefániková, J.; Ď́ranová, H.; Kowalczewski, P.; Kačániová, M. Thymus serpyllum Essential Oil and Its Biological Activity as a Modern Food Preserver. Plants 2021, $10,1416$. [CrossRef]

53. Guimarães, A.C.; Meireles, L.M.; Lemos, M.F.; Guimarães, M.C.C.; Endringer, D.C.; Fronza, M.; Scherer, R. Antibacterial Activity of Terpenes and Terpenoids Present in Essential Oils. Molecules 2019, 24, 2471. [CrossRef]

54. Marchese, A.; Arciola, C.R.; Barbieri, R.; Silva, A.S.; Nabavi, S.M.; Sokeng, A.J.T.; Izadi, M.; Jafari, N.J.; Suntar, I.; Daglia, M.; et al. Update on Monoterpenes as Antimicrobial Agents: A Particular Focus on p-Cymene. Materials 2017, 10, 947. [CrossRef]

55. Togashi, N.; Inoue, Y.; Hamashima, H.; Takano, A. Effects of Two Terpene Alcohols on the Antibacterial Activity and the Mode of Action of Farnesol against Staphylococcus aureus. Molecules 2008, 13, 3069-3076. [CrossRef]

56. Lorenzi, V.; Muselli, A.; Bernardini, A.F.; Berti, L.; Pagès, J.-M.; Amaral, L.; Bolla, J.-M. Geraniol Restores Antibiotic Activities against Multidrug-Resistant Isolates from Gram-Negative Species. Antimicrob. Agents Chemother. 2009, 53, 2209-2211. [CrossRef] [PubMed]

57. Hrytsyna, M.R.; Kryvtsova, M.V.; Salamon, I.; Skybitska, M.I. Promising ex situ essential oil from Thymus camphoratus (Lamiaceae). Regul. Mech. Biosyst. 2020, 11, 315-322. [CrossRef]

58. Kryvtsova, M.V.; Salamon, I.; Koscova, J.; Bucko, D.; Spivak, M. Antimicrobial, antibiofilm and biochemichal properties of Thymus vulgaris essential oil against clinical isolates of opportunistic infections. Biosyst. Divers. 2019, 27, 270-275. [CrossRef]

59. Adams, R.P. Identification of Essential Oil Components by Gas Chromatography/Mass Spectrometry, 4th ed.; Allured Publishing Corporation: Carol Stream, IL, USA, 2007; ISBN 978-1-932633-21-4.

60. Obistioiu, D.; Cocan, I.; Tîrziu, E.; Herman, V.; Negrea, M.; Cucerzan, A.; Neacsu, A.-G.; Cozma, A.; Nichita, I.; Hulea, A.; et al. Phytochemical Profile and Microbiological Activity of Some Plants Belonging to the Fabaceae Family. Antibiotics 2021, 10, 662. [CrossRef]

61. Alexa, V.T.; Galuscan, A.; Popescu, I.; Tirziu, E.; Obistioiu, D.; Floare, A.D.; Perdiou, A.; Jumanca, D. Synergistic/Antagonistic Potential of Natural Preparations Based on Essential Oils Against Streptococcus mutans from the Oral Cavity. Molecules 2019, 24, 4043. [CrossRef] [PubMed]

62. Costa, L.C.B.; Pinto, J.E.B.P.; Bertolucci, S.K.V.; Costa, J.C.D.B.; Alves, P.B.; Niculau, E.D.S. In vitroantifungal activity of Ocimum selloi essential oil and methylchavicol against phytopathogenic fungi. Rev. Cienc. Agron. 2015, 46, 428-435. [CrossRef] 